\title{
Mechanical behaviour of grouted sleeve splice under uniaxial tensile loading
}

Zhiwei Lu', Jun Huang, ${ }^{\mathrm{a}, *}$, Yubo Li ${ }^{\mathrm{a}}$, Shaobin Dai ${ }^{\mathrm{a}}$, Zhong Peng ${ }^{\mathrm{a}}$, Xuan Liu ${ }^{\mathrm{a}}$, Mingzhong Zhang,"*

${ }^{a}$ School of Civil Engineering and Architecture, Wuhan University of Technology, Wuhan 430070, China

${ }^{b}$ Department of Civil, Environmental and Geomatic Engineering, University College London, London WC1E 6BT, UK

Abstract: This paper presents an experimental and analytical study on mechanical behaviour of two kinds of new low-cost grouted sleeves processed by seamless steel pipe, i.e., grouted sleeve with wedge and grouted sleeve with wedge and thread, under uniaxial tension. In total, twenty-two rebar splice specimens with various embedded lengths, spliced bar diameters and wedge lengths are prepared and tested. The test results indicate that the performance of both grouted splices meets the requirements of ACI318 and JGJ107. The required embedded length of rebar in the splice is found to be around 6-6.4 times the spliced bar diameter due to confinement effect. The tensile capacity of the splice increases with increasing diameter of the anchorage segment of the spliced bar, and length and slope of the wedge at both ends of the sleeve. Because of the good performance of wedges threads do not significantly improve the tensile capacity of the sleeve but improve the bond strength and bearing capacity in non-wedge segment of the sleeve. The tensile capacity of the specimen is slightly lower than that of steel bar and the reduction coefficient of bearing capacity is estimated. An analytical model is proposed to predict the tensile capacity of grouted sleeves considering the effects of confinement and reduction of tensile capacity of the splices, the predictions of which are in good agreement with experimental data.

Keywords: Grouted sleeve; Confinement; Embedded length; Bond strength; Analytical model

\section{Introduction}

Precast concrete structures are increasingly replacing conventional concrete structures because of their remarkable advantages, such as shorter construction time, lower cost, less energy consumption, better quality of the components, and easier quality control [1,2]. However, the complexity and efficiency of the connection of steel bars between precast concrete structural members may hinder widespread application of precast concrete structures. In recent years, many attempts have been made to address the problems of steel bar connection in precast concrete structures, which include

\footnotetext{
* Corresponding authors. E-mail address: hj@whut.edu.cn (J. Huang); mingzhong.zhang@ucl.ac.uk (M. Zhang)
} 
the use of steel lapped splices [3,4], steel bar welding splices [5] and mechanical splices (dry connections) [6]. However, the steel lapped splices often lead to bar congestion problems [7,8], while it is difficult to construct the steel bar welding splices and guarantee the welding quality, and the mechanical splices require very tight tolerances in precast production, which is still a challenge to most precast manufacturers [9].

More recently, the grouted sleeve splice has gathered increasing attention as a replacement for other splices because of its special working mechanism, controllable tolerance, no need to weld at construction site and accelerated construction [10-13]. The grouted sleeve splice is formed by inserting connecting steel bars into a sleeve and pouring high-strength and slightly-expanding cement-based grout. A typical example of commonly used grouted sleeve splices is shown in Fig. 1. However, the commercially available grouted sleeves (i.e. proprietary grouted sleeves) such as Lenton Interlok, NMB Splice Sleeve and TTK Tops-joint are expensive due to complex manufacturing processes and the use of high-strength materials [14]. In order to reduce the cost of the grouted sleeves, using ordinary seamless steel pipes to make grouted sleeves is considered as a solution to replace the commercial grouted sleeves [15].

In 1995, Einea et al. [16] firstly proposed the idea of using ordinary steel tubes to make the grouted sleeves and developed the sleeve named as non-proprietary grouted sleeve. Based on a series of tests, they found that high bond strength of spliced bar can be obtained by confining the grout surrounding the steel bars using the steel pipe. Since then, some efforts have been made to develop new non-proprietary grouted sleeves and investigate the behaviour of them. For example, Ling et al. [7] investigated the tensile behaviour of four series of grouted sleeves with different configurations and concluded that configurations of the sleeve have a significant influence on the bond strength between bar and grout and the required anchorage length is 9 times the bar diameter. However, the performance of these sleeves is not good enough for structural application. Two types of grouted sleeves, i.e., welded bar sleeve (WBS) and tapered head sleeve (THS), were proposed by Ling et al. $[15,17]$, who observed that the tensile capacity of THS is $30 \%$ higher than that of WBS due to more effective confinement provided by the tapered sleeve wall, which improves the bond strength between the spliced bar and the grout. The required embedded length of the spliced bar was found to be 8 times the rebar diameter. However, the manufacturing process of THS is very complicated and it is hard to fix THS due to its unique tapered shape of THS, which may limit its widespread application. Hosseini et al. [18] developed a grouted spiral connection and reported that 
the confinement provided by the spiral could significantly improve the bond performance between bars and grout and the confinement effect can be greatly enhanced by reducing the diameter of the spiral. However, the spiral connections need longer embedded length of the spliced bar than the grouted steel pipe splices due to the much lower confinement provided by the spiral than that provided by the steel pipe. Henin et al. [9] developed a non-proprietary grouted splice sleeve and discussed the design method of the proposed sleeve. Alias et al. [8,19] made a composite grouted sleeve by using two kinds of steel pipes. The smooth contact between the inner sleeve of the sleeve and the grout makes the bond failure of the inner sleeve prone to occur and thus weakens the bond strength of the spliced bar. Besides, the required anchorage length of spliced bar is more than 10 times bar diameter. Sayadi et al. [20] explored the effect of interlocking mechanism on bond strength of grouted sleeve splices. They used bolts to provide interlocking mechanism and found that providing interlocking mechanism in the elastic segment of the sleeve results in a decrease in bond strength of the grouted sleeve splice while providing interlocking mechanism in the inelastic segment of the sleeve makes the splice perform better. However, the influences of bolt size and shape on bond strength in the elastic segment and inelastic segment of grouted sleeve splices were not considered. In addition, the resistance of sleeves connecting two spliced bars through bolts to slipping of the spliced bar was not good enough.

In summary, the production methods of existing non-proprietary sleeves are still complicated. The required embedded length of the spliced bar is more than 8 times the bar diameter (i.e. the length of the sleeve is more than 16 times the bar diameter), which is longer than that of proprietary sleeves. The existing non-proprietary sleeves do not show significant advantages (e.g., easy to produce, low cost, good performance, etc.) compared to proprietary sleeves.

To address these disadvantages of existing non-proprietary sleeves a combination of ordinary steel tube and wedge in a composite system by welding is proposed in this study to make new low-cost non-proprietary grouted sleeves that can be used in actual assembly structures easily and cheaply. Fig. 2 shows the schematic diagram of such sleeves that are named as grouted sleeve with wedge (GSW) and grouted sleeve with wedge and thread (GSWT). GSW can be conveniently and economically produced because of its unique advantage compared to existing sleeves that regardless of the size and length of the sleeve required, it is only needed to weld two short wedges at both ends of the sleeve. The cost of GSWT would be slightly higher than GSW due to threads in sleeve but still much cheaper than other sleeves. The small threads in GSWT can be used to study the effect of 
interlocking mechanism of small ribs on the performance of the sleeve in comparison with GSW and thus to assess whether it is necessary to use ribs in the non-wedge segment of the sleeve to improve the overall performance of GSW.

In this study, for the first time, a thorough understanding of the mechanical behaviour of GSW and GSWT under uniaxial tension is provided. The effects of embedded length, diameter of spliced bar and wedge length on the performance of grouted splices under tensile loading are estimated through a series of tests. The mechanism of force transfer of grouted splices is analysed and discussed. Besides, an analytical model is proposed based on previous studies $[15,16,21,22]$ to predict the tensile capacity of grouted splices. The predictions are compared with experimental results.

\section{Experimental program}

\subsection{Materials}

The low alloy seamless steel pipes with an outer diameter $\left(D_{s}\right)$ of $51 \mathrm{~mm}$ were used to produce GSW and GSWT, while wedge was made from steel pipes with an external diameter of $40 \mathrm{~mm}$. The properties of steel pipes are given in Table 1. Two types of steel bars with diameters of $20 \mathrm{~mm}$ and $22 \mathrm{~mm}$ were used in the experiments, the properties of which are listed in Table 2. The grout with an average compressive strength and flexural strength of 79.2 $\mathrm{MPa}$ and 15.1 $\mathrm{MPa}$ respectively that were tested on prism specimens $(40 \times 40 \times 160 \mathrm{~mm})$ in accordance with JG/T408 [23] was used in this study.

\subsection{Specimen preparation}

Fig. 3 shows the details of the GSW and GSWT specimens, in which the thickest part of the wedge is $4 \mathrm{~mm}$, while the thinnest part is about $1 \mathrm{~mm}$. Two wedges were welded at both ends of the sleeve. The main difference between GSWT and GSW is that GSWT contains built-in threads, as shown in Fig. 3b. Fig. 4 show the production process of the sleeves that consists of five steps: (1) two types of low alloy steel pipes are chosen (one large and one small) and the outer diameter of the small steel pipe is kept the same as the inner diameter of the large steel pipe; (2) cut the steel pipes into a specified length; (3) process the wedges by using the small steel pipes as raw materials; (4) make internal threads by using the large steel pipes for GSWT; (5) weld the wedges at both ends of the large steel pipes.

For measuring the mechanical properties of grouted sleeves GSWT and GSW, twenty-two grouted sleeve splice specimens were designed and fabricated for uniaxial tensile test, as shown in 
Fig. 5. Table 3 lists the details of the specimens corresponding to those shown in Fig. 3. For labels GW-D20-1 and GT-D20-1, "GW" and "GT" stand for types of sleeve of GSW and GSWT, respectively, "D20" represents the spliced bar diameter of $20 \mathrm{~mm}$, and " 1 " denotes the specimen number.

\subsection{Testing method}

Uniaxial tensile test was performed on specimens after 28 days of curing by using a $1000 \mathrm{kN}$ electro-hydraulic servo material testing machine, as shown in Fig. 6. The entire test and measurement were carried out under displacement control. The crosshead displacement rate was 0.5 $\mathrm{mm} / \mathrm{min}$ [24]. The load and displacement of the actuator are automatically recorded by the electric-hydraulic loading system. During the tests, five longitudinal strain gauges (SG1-SG5) and five transverse strain gauges (SG6-SG10) were symmetrically affixed along the sleeve to measure the strain variation of the sleeve under loading, as shown in Fig. 7. An automatic data acquisition system was utilized to monitor loading and strains.

\section{Experimental results}

\subsection{Failure modes}

Fig. 8 shows the failure modes of the grouted sleeve specimens: spliced bar fracture and bond-slip failure, which means that the tensile capacity of the splices exceeds or is lower than the tensile capacity of the spliced bar itself, respectively. It can be found that only three specimens, i.e. GW-D20-4 $\left(L_{2}=6 d_{n}\right)$, GT-D20-1 $\left(L_{2}=6 d_{n}\right)$ and GT-D22-11 $\left(L_{2}=5.5 d_{n}\right)$, were subjected to bond-slip failure. The anchorage length of the three specimens with bond-slip failure was kept as $120 \mathrm{~mm}$. The main reasons for bond-slip failure are as follows: (1) when the anchorage length of the rebar is short, the number of the ribs on the spliced bar and the contact area of the spliced bar with the grout are small. As a result, the bond force between the spliced bar and the grout is small; (2) after yielding of the steel bars, the axial elongation of them are increased and the cross-sectional area of them becomes smaller due to Poisson's effect. These result in a reduction of the clamping effect of the grout to the steel bar and the friction between the rebar surface and the grout as well as the bearing capacity of ribs on grout keys, which affects the bond capacity accordingly [25].

No cracks of the grout were observed at the end of the sleeves before the specimen yielded. However, after the specimen yielded, it was observed that the superfluous grout which was not restrained by the sleeve outside the anchoring length of the spliced bar at the end of the sleeve was pulled out slowly. When the specimen was broken, a loud noise was heard instantly. Afterwards, the 
extra grout pulled out on the steel bar was hopped off, and grout cone was formed at the end of the sleeve [26], while the grout in the sleeve was not pulled out in all specimens and the weld at the end of the sleeve was intact.

\subsection{Load-displacement curves}

Fig. 9 shows the typical load-displacement curves of the spliced sleeve specimens. The curves consist of elastic, yielding, strengthening and tightening regions that look similar to those for steel bars under uniaxial tension. This indicates that the sleeve can provide effective constraints, which enhance the bond strength between the grout and spliced bar. Consequently, the two disconnected bars were perfectly connected into the continuous steel bar. The load-displacement curves of the two types of spliced sleeves basically coincided except the displacement at the failure points. The failure displacement of GSW was larger than that of GSWT, which indicates that the structure of the sleeve cavity had a certain influence on the extension performance of the splice, as shown in Fig. 9b and $9 \mathrm{c}$. For the same sleeves, the ultimate bearing capacity was significantly increased when the spliced bar is increased from $20 \mathrm{~mm}$ to $22 \mathrm{~mm}$ (see Fig. 9d).

The bond force between the spliced bar and the grout was less than the tensile capacity of spliced bar, as a result of which the tooth key between the spliced bar and the grout was cut off when the specimens (GW-D20-4, GT-D20-1 and GT-D22-11) entered the strengthening stage. Finally, a sliding plane formed, and bond failure occurred in these specimens. It can be observed from Fig. 9a and 9d that the residual load bearing capacity of the specimen with bond-slip failure was about $60 \%$ of the ultimate bearing capacity of the specimen. Hence, the residual load bearing capacity remained high.

\subsection{Load-strain response}

Fig. 10 shows the load-strain curves of the specimens. The strain is positive for tensile strain and negative for compressive strain. As seen in Fig. 10, the longitudinal strain of all specimens was tensile strain, while the transverse strain was mainly compressive strain. The longitudinal and transverse strain at the middle of the sleeve always followed a linear response (see Fig. 10b). The other measuring points also showed a linear response in terms of both longitudinal and transverse strain before yielding, but after the specimen yielded the longitudinal strain tended to be compressive strain and the transverse strain became tensile strain, which can be attributed to the splitting cracks occurred around the connecting steel bar in the case of high tensile load resulting in the expansion of the sleeve [27]. The sleeve with higher strength and stiffness can prevent its 
expansion, which consequently reflected the active restraint effect of the sleeve. The maximum longitudinal strain in the sleeve was found to be $1349 \times 10^{-6}$ (that is much lower than the yield strain, $1893 \times 10^{-6}$ ) and the maximum transverse strain was $-317 \times 10^{-6}$. All the measured strain indicates that the sleeves did not yield along either longitudinal or transverse directions and met the strength requirements.

Fig. 11 shows the longitudinal strain distribution curves for the specimens GW-D20-2 and GT-D20-2 $\left(L_{1}=40 \mathrm{~mm}\right.$ and $\left.L_{2}=7.0 d_{n}\right)$ at different positions along the axial direction of the sleeve at loads of $50 \mathrm{kN}, 100 \mathrm{kN}, 150 \mathrm{kN}$ and $180 \mathrm{kN}$. The strain curve of the specimen GW-D20-2 was in an inclined roof shape, while the strain curve of the specimen GT-D20-2 followed an arched shape. The strain curves of the two specimens were symmetrically distributed along the central axis of the sleeve. The longitudinal strain curve of GW-D20-2 became uniformly attenuated from the middle of the sleeve to the end, but the longitudinal strain curve of GT-D20-2 reduced slowly followed by a rapid decrease from the middle to the end.

Fig. 12 shows the transverse strain distribution curves for the specimens GW-D20-2 and GT-D20-2 at different positions along the axial direction of the sleeve at loads of $50 \mathrm{kN}, 100 \mathrm{kN}$, $150 \mathrm{kN}$ and $180 \mathrm{kN}$. The strain of SG8 gradually increased with the increase of tensile load. As the tensile load increased, the strain of SG7 and SG9 increased but tended to be tensile strain when the tensile load approached to $150 \mathrm{kN}$ and became tensile strain when the tensile load reached to 180 $\mathrm{kN}$. The strain of SG6 and SG10 at both ends of the sleeve increased with the increase of tensile load, but for GW-D20-2 the strain varied more greatly compared to GT-D20-2.

\subsection{Mechanical behaviour of grouted splice}

\subsubsection{Feasibility evaluation}

The following yield ratio $\left(R_{y}\right)$, strength ratio $\left(R_{S}\right)$ and ductility ratio $\left(R_{d}\right)$ proposed by Ling [17] were used in this study to evaluate the mechanical properties of the grouted splices that are presented in Table 4.

$R_{y}=\frac{f_{y s t}}{f_{s y k}}$

$R_{s}=\frac{f_{u s t}}{f_{s y k}}$

$R_{d}=\frac{\delta_{u}}{\delta_{y}}$

where $f_{y s t}$ denotes the yield strength of specimen (i.e. the load at yield over cross-sectional area of steel bar), $f_{s y k}$ represents the specified yield strength of steel bar, $f_{u s t}$ is the ultimate tensile 
strength of specimen (i.e. the ultimate tensile load over cross-sectional area of steel bar), $\delta_{u}$ is the maximum displacement, and $\delta_{y}$ is the displacement at yield.

According to JG/T 398 [28] and JGJ 107 [24], the ultimate tensile strength of the splice $\left(f_{\text {ust }}\right)$ can be classified into three grades (see Table 5). It should be noted that the fracture of the spliced bar means that the failure of the specimen occurs in the connecting steel bar itself, and connector damage refers to sleeve fracture, longitudinal cracking of sleeve, other connection components failure and the pull-out of the connecting steel bar from the sleeve. In Table 5, $f_{\text {stk }}$ stands for the specified tensile strength of steel bars in the specimen. As per ACI318 [29], the ultimate tensile strength $\left(f_{u s t}\right)$ of the splice should be greater than 1.25 times the specified yield strength $\left(f_{\text {syk }}\right)$ of the connecting steel bars. It can be seen from Table 4 that both the specimens GW-D20-4 and GT-D20-1 meet the strength grade II, and the rest specimens meet the strength grade I. Moreover, all specimens meet the strength requirements of ACI318. Yield ratio $\left(R_{y}\right)$ is used to determine whether the specimen yields. JGJ355 [30] stipulates that the tensile strength of the grouted sleeve splice should not be less than the specified yield strength of the connecting steel bar. In addition, the ductility ratio $\left(R_{d}\right)$ should be at least 4.0 for low-moderate seismic regions in accordance with ACI-318 and BS8110 [31]. As seen in Table 4 that all specimens meet the ductility and yield requirements except specimen GT-D22-11.

\subsubsection{Effect of weld}

It can be assumed that the contact between the wedge and the steel pipe is smooth because of the very small friction between them, and the force acting on the wedge is fully transferred to the sleeve through the weld, as demonstrated in Fig. 13. The yield bearing capacity and ultimate bearing capacity of the weld can be calculated as [32]

$\frac{N}{h_{e} l_{w}} \leq f_{w}$

$h_{e}=0.7 h_{f}$

where $N$ is the yield or ultimate bearing capacity of the weld, $h_{e}$ is the effective foot length, $l_{w}$ is weld length, $f_{w}$ is weld strength and $h_{f}$ is the welding foot length.

Because all the sleeves did not yield, the maximum load on the wedge $\left(P_{w}\right)$ during the whole test process can be expressed as:

$P_{w}=\varepsilon_{s l} E_{m} A_{s}$

where $\varepsilon_{s l}$ is the longitudinal strain of sleeve (the maximum value of average strain of SG1 and 
SG5 is taken), and $E_{m}$ and $A_{s}$ are the elastic modulus and cross-sectional area of the sleeve, respectively.

Since the wedge fully transfers the load to the sleeve through the weld, the maximum load acting on the wedge is equal to the load acting on the weld. Fig. 14 shows a comparison between the actual maximum load on the weld in the test and its own bearing capacity, which indicates that the weld did not yield and showed a high safety reserve.

\subsubsection{Effect of spliced bar}

Fig. 15 shows a comparison of load bearing capacity of the specimens with various embedded lengths. The load bearing capacity of the splice was increased by $25.5 \%$ when the diameter of the spliced bar with embedment length $120 \mathrm{~mm}$ increased from $20 \mathrm{~mm}$ to $22 \mathrm{~mm}$, which can be explained by the fact that (1) the contact area between the connecting steel bar and the grout was increased with increasing diameter of the connecting steel bar, and the force transfer between the grout and the connecting steel bar was strengthened, and (2) the thin grout surrounding the spliced bar reduced the allowable deformation of grout and decreased the stress absorption property of the grout, which subsequently made the constraint response provided by the sleeve sensitive to the splitting expansion of the grout $[17,33]$. Therefore, the load bearing capacity of the sleeve splice can be increased by increasing the diameter of spliced bar in the range of anchorage length. In addition, the anchorage length of steel bar can be reduced by this method to shorten the length of grouted sleeve in order to reduce the cost. Furthermore, the tensile capacity was improved with the increase of the anchorage length of spliced bar. As the anchorage length of spliced bar with a diameter of 22 $\mathrm{mm}$ increased from $120 \mathrm{~mm}$ to $140 \mathrm{~mm}$ the load carrying capacity was increased by $1.8 \%$.

\subsubsection{Effect of wedge}

In order to reduce the influence of eccentricity of the steel bar and inhomogeneity of the grout on the test results, the measured ultimate load of the specimen with the same wedge size was averaged and plotted in Fig. 16. For GSW and GSWT, when the wedge length in the sleeve was less than 30 $\mathrm{mm}$, the ultimate bearing capacity of the specimen was mainly affected by the slope $\beta$ : the greater the slope of the wedge, the higher the ultimate bearing capacity of the specimen. When the length of the wedge was more than $30 \mathrm{~mm}$, the ultimate bearing capacity of the specimen was mainly influenced by the length of the wedge: the longer the wedge, the higher the ultimate bearing capacity.

\section{Analysis and discussion}




\subsection{Mechanism of force transfer in the connection}

This section discusses the mechanism of force transfer in the two types of spliced sleeve connection (i.e., GSW and GSWT). The initial stress is generated inside the sleeve of the specimen due to the micro-expansion effect of the grout. However, this initial stress is small [34] and thus can be ignored when analysing the force transmission mechanism that is demonstrated in Fig. 17.

For GSW, the transmission of pulling force mainly depends on the wedging action of the ribs on the steel bar and the wedging action of the wedge in the sleeve on grout to realise the effective transmission of tensile force, as shown in Fig. 17a. The action of the sleeve on the grout can be divided into two segments: a wedge segment and a non-wedge segment. Regarding wedge segment when the steel bar transfers the force to the grout, there is an interaction between the grout and the wedge and the wedge exerts active confinement force on the grout. This active confinement force can be resolved into normal and longitudinal force [18]. Normal componential stress exerts radial confinement on the grout to resist or delay the propagation of the tensile splitting cracks caused by the wedging action of spliced bar, as seen in Fig. 18. Meanwhile, the longitudinal componential stress that is parallel to the grouted sleeve axis prevents the slippage of the grout and the rib of rebar interlocked by the grout shear key from moving horizontally [18]. In regard to non-wedge segment the force of sleeve acting on the grout can also be decomposed into normal and longitudinal force (see Fig. 17a). Normal componential stress mainly comes from two aspects: (1) radial confinement stress caused by Poisson's effect while the sleeve extends along the axial direction, and (2) confinement stress in the sleeve due to wedge action of steel bar that causes grout to split and expand along radial direction, as shown in Fig. 18. Consequently, this normal componential stress acts as passive confinement for sleeve in non-wedge segment. However, the longitudinal componential stress depends on chemical adhesion and friction between sleeve and grout [10]. Moreover, it should be noted that the grout in non-wedge segment also bears the horizontal force induced by the wedging action of the wedge (see Fig. 17a).

For GSWT, the transmission of pulling force mainly depends on the wedging action of ribs on the steel bar, the wedging action of the wedge in the sleeve on grout, and the interlocking mechanism caused by built-in threads between the sleeve and the grout, as shown in Fig 17b. The action of the sleeve on the grout can also be divided into two segments: a wedge segment and a non-wedge segment. The mechanism of force transfer of GSWT in wedge segment is the same as that of GSW. However, the mechanism of force transfer of GSWT in non-wedge segment is 
different from GSW. Longitudinal componential stress of GSWT in non-wedge segment is a result of not only the chemical adhesion and friction but also the interlocking caused by threads between the sleeve and the grout.

Since the friction between the wedge and the sleeve is small and can be ignored, it can be assumed that the force on the wedge is fully transmitted to the sleeve through the weld. In order to estimate the effect of threads on the performance of the sleeve and the wedge segment and the non-wedge segment of the two types of the sleeves, the ultimate bearing capacity of wedge segment $\left(P_{w}\right)$ and non-wedge segment $\left(P_{g}\right)$ calculated by Eqs. (6) and (7) for GSW and GSWT is presented in Tables 6 and 7, respectively. The bond stress at the sleeve-grout interface in non-wedge segment $\left(\tau_{g}\right)$ can be calculated using Eq. (8) along with Eq. (9).

$P_{g}=P_{u}-P_{w}$

$\tau_{g}=\frac{P_{g}}{\pi\left(D_{s}-2 t_{b}\right) L_{3}}$

$L_{3}=L_{2}-L_{1}$

where, $D_{s}$ denotes the outer diameter of the sleeve, $t_{b}$ is the thickness of the sleeve, $L_{2}$ is the bar embedment length, and $L_{1}$ and $L_{3}$ is the length of wedge segment and non-wedge segment, respectively.

The test results shown in Fig. 16 indicate that the tensile capacity of GSWT is close to that of GSW (only $0.39 \%$ higher than that of GSW). As seen in Tables 6 and 7, the bearing capacity of non-wedge segment of GSWT is $19 \%$ higher than that of GSW, while the bearing capacity of wedge segment of GSWT is $76 \%$ lower than that of GSW. These imply that the threads in GSWT do not significantly improve its tensile capacity in comparison with GSW under uniaxial tensile loading. However, it can be found that the small threads (thread depth $=1.5 \mathrm{~mm}$ ) can help improve the distribution of load carrying capacity of the sleeve and increase the bond strength and bearing capacity in non-wedge segment of the sleeve. This can be attributed to the interlocking mechanism provided by the threads in GSWT that enhances the friction and bond stress between the inner wall of the sleeve and the grout. This finding is consistent with that reported in $[14,35]$ that the maximum load of the sleeve increased when the height of the rib (not thread) providing interlocking mechanism increased from $1.0 \mathrm{~mm}$ to $1.5 \mathrm{~mm}$. Therefore, the use of small size and small-spaced ribs such as small threads and conical ribs in the grouted sleeve can provide interlocking mechanism and consequently help improve the distribution of load carrying capacity of the grouted sleeve. 
It should be noted that the bearing capacity of the wedge segment is higher than the value calculated in this paper. Consequently, the bearing capacity of both GSW and GSWT in the wedge segment has a large surplus, especially GSWT.

\subsection{Analytical analysis}

In order to predict the tensile capacity of the two types of grouted sleeves, an analytical model is established and validated in this section. The derivation of this analytical model is explained in detail below.

Due to the fact that a wide range of factors influence the bond strength distribution at the bar-grout interface and the actual bond strength distribution is still too complex to measure, an assumption of uniform bond strength distribution along the embedded length of the spliced bar is used for simplification [36,37]. This assumption was also utilised by other researchers to study the grouted sleeves with different configurations and has been proven to be appropriate $[7,9,10,15-18,20,38,39]$. The relationship between the bond force of GSW and GSWT splices $\left(P_{n}\right)$, i.e. the load carrying capacity of the sleeve splice, and the average bond strength of the connecting steel bar $\left(u_{i}\right)$ can be expressed as [40]:

$P_{n}=\pi d_{n} L_{2} u_{i}$

where $d_{n}$ is the diameter of the spliced bar, and $u_{i}$ represents the average bond strength of the spliced bar that can be derived from [21]:

$u_{i}=\left(C+D \sqrt{u_{g j}}\right) \sqrt{f_{u g}}$

where $C$ and $D$ are constants related to the types of the sleeve, $u_{g j}$ is the average confinement stress of the grout acting on the connecting steel bar, and $f_{u g}$ is the compressive strength of the grout (i.e. 79.2 $\mathrm{MPa}$ in this study).

It is indicated that the confinement stress of the grout acting on the connecting steel bar can be uniform through the embedded length of the spliced bar for analysis. According to Zheng et al. [10] and Ling et al. [15], the confinement force acting on the steel bar can be equivalent to the confinement force caused by the grouted sleeve. Consequently, the confinement stress of the sleeve acting on the grout can be uniform through the embedded length of the spliced bar by assuming that the confinement stress generated by the sleeve distributes evenly over the embedment length of the steel bar. The assumption has been commonly used and proved to be acceptable, although the effects of local confinement stress and bond strength generated by the different configurations of the sleeves were ignored $[15,16,22,38]$. This assumption is used herein as well for simplifying the 
derivation process and thus the confinement stress of the grout acting on the connecting steel bar $\left(u_{g j}\right)$ can be calculated by Eq. (12). In Eq. (12) $F_{n}$ is the confinement force of the grout acting on the spliced bar that equals to the confinement force of the sleeve acting on the grout. The confinement force acting on the grout $\left(F_{n}\right)$ is equal to the confinement stress acting on the grout $\left(u_{n}\right)$ multiplied by the inner surface area of the sleeve $\left(A_{m l}\right)[15]$.

$u_{g j}=\frac{F_{n}}{\pi d_{n} L_{2}}$

$F_{n}=u_{n} A_{m l}$

$A_{m l}=A_{1}+A_{2}$

$A_{1}=\pi d_{t n} L_{3}$ (for non-wedge segment of sleeve)

$A_{2}=\frac{\pi\left(L_{1}-5\right)}{2 \cos \beta}\left(d_{t n}+d_{m n}\right)+5 \pi d_{m n}$ (for wedge segment of sleeve)

As demonstrated in Fig. 19, the relationship between the transverse tensile force $\left(T_{s}\right)$ and the confinement stress $\left(u_{n}\right)$ in the sleeve can be expressed as a function of the inner diameter of non-wedge segment in the sleeve $\left(d_{t n}\right)$ and the embedment length of the steel bar $\left(L_{2}\right)$ as follows:

$2 T_{s}=u_{n} d_{t n} L_{2}$

According to the strain collected, all the sleeves did not yield. Thus, the transverse tensile stress of sleeve $\left(f_{s d}\right)$ is equal to the circumferential strain $\left(\varepsilon_{s t}\right)$ multiplied by the elastic modulus $\left(E_{m}\right)$ of the sleeve and is related to the transverse tensile force $\left(T_{S}\right)$, as suggested in $[15,16,22]$.

$f_{s d}=\varepsilon_{s t} E_{m}$

$f_{s d}=\frac{T_{s}}{t_{b} L_{2}}$

$T_{s}=\varepsilon_{s t} L_{2} t_{b} E_{m}$

Therefore, the confinement stress $\left(u_{n}\right)$ in Eq. (13) can be expressed as:

$u_{n}=\frac{2 \varepsilon_{s t} t_{b} E_{m}}{d_{t n}}$

According to Eq. (11), $C$ and $D$ are found to be 1.97 and 0.145 by linear regression analysis of experimental data, as shown in Fig. 20. Substituting Eq. (11) and the values of $C$ and $D$ into Eq. (10), the bond force of grouted sleeve $\left(P_{n}\right)$ can be expressed as:

$P_{n}=\pi d_{n} L_{2} \sqrt{f_{u g}}\left(1.97+0.145 \sqrt{u_{g j}}\right)$

Due to the influences of the grouted sleeve and eccentricity of connecting steel bars [41], the ultimate bearing capacity of the specimen is different from the ultimate bearing capacity of the steel bar (see Fig. 21), which has the following relationship: 
$\alpha=\frac{P_{j}}{P_{c}}$

where $\alpha$ is the reduction coefficient of bearing capacity, $P_{j}$ is the average ultimate load when the spliced bar of the splice breaks, and $P_{c}$ is the measured ultimate load for steel bar.

Thus, the tensile capacity of the spliced bar $\left(F_{\mathrm{b}}\right)$ can be expressed as $F_{b}=\alpha P_{c}$

When $P_{n} \geq F_{b}$, the actual value $P_{u}$ is equal to $F_{b}$. Otherwise, the value $P_{u}$ is equal to $P_{n}$. A ratio $\left(R_{c}\right)$ is used to compare the predicted tensile capacity $\left(P_{u, p r e},\right)$ and the experimental results in terms of tensile capacity $\left(P_{u, e x p},\right)$.

$R_{c}=\frac{P_{u, \text { exp }}}{P_{u, p r e}}$

Fig. 21 shows a comparison of the tensile capacity of grouted sleeves and steel bar. The average tensile capacity of specimen with connecting bar diameter of $20 \mathrm{~mm}$ for bar fracture failure is $182.24 \mathrm{kN}$, while the measured tensile capacity of steel bar is $185.80 \mathrm{kN}$. The corresponding reduction coefficient of bearing capacity $(\alpha)$ is found to be 0.98 , which indicates that the bearing capacity of the grouted sleeve splice is slightly lower than the tensile capacity of the connecting steel bar itself. This can be attributed to the failure mode and eccentricity of the embedded bars $[41,42]$, as showed in Fig. 22. It is difficult to ensure that there is no eccentricity between the steel bar and the sleeve when making the specimens. When the specimen was subjected to tensile load, the load could cause the specimen to inevitably self-align and rotate [43]. This deformation causes the spliced bar not only to be subjected to axial tensile force but also to torque and shear force (see Fig. 22a). These forces can result in undesired stress on the steel bar and nonuniform stress distribution in the section of the spliced bar. Therefore, the eccentricity of spliced bar leads to local and earlier failure of grouted sleeve splice and a slight decrease in tensile capacity. As a result, the failure section of the spliced bar is a slope, which is different from the failure of a single steel bar subjected to purely axial load, as shown in Figs. $22 \mathrm{~b}$ and 23 . The failure mode of grouted sleeve connection can be judged using the tensile capacity of the steel bar. If the predicted bond force is less than the tensile capacity of the steel bar, the grouted sleeve splice is considered to have a rebar bond-slip failure. Otherwise, the grouted sleeve splice would endure rebar fracture outside the sleeve.

Based on experimental data, the corresponding parameters are substituted into above equations to predict the tensile capacity of the grouted sleeves. The prediction results together with 
experimental data are presented in Table 8 . The reliability ratio $\left(R_{c}\right)$ was found to be in the range of 0.99 to 1.10 for GSWT except only one specimen GT-D20-1 with a $R_{c}$ of 1.13. A similar result can be observed for GSW. This indicates that the predicted tensile capacity shows a good agreement with measured tensile capacity. The predict failure models of GSWT match $77 \%$ of the failure modes observed in the tests while the predicted failure modes of GSW only match $56 \%$ of those of experimental findings. Therefore, GSWT is more accurate than GSW in terms of predicted failure modes. In addition, as stated in [15] that the sleeve diameter may influence the degree of confinement stress and thus the tensile capacity of the grouted sleeves. In this study, only a constant diameter of $51 \mathrm{~mm}$ was considered in the analytical model. More tests on grouted sleeves with various diameters will be conducted to further validate the feasibility of this model for specimens with other diameters, the results of which will be presented in future publications.

\section{Conclusions}

In this work, two types of grouted sleeves (GSW and GSWT) were developed with seamless steel pipe by turning and welding. In total, twenty-two specimens of grouted sleeve splices were prepared and measured to investigate mechanical behaviour of them under uniaxial tensile loading. Based on the experimental results and analytical analysis, the main conclusions can be drawn as follows:

- All specimens met the JGJ107 strength requirements of the splice grade I except the specimens GW-D20-4 and GT-D20-1 and the tensile strength of all specimens was found to be more than 1.25 times the specified yield strength of the spliced bars required by ACI318. These indicate that it is feasible for GSW and GSWT to connect two disconnected steel bars.

- The ultimate load of all specimens was slightly lower than that of reinforced steel bar, which can be ascribed to the fact that the spliced bars at both ends of the sleeve may not be on the same axis. In addition, the reduction coefficient of bearing capacity is found to be 0.98 for GSW and GSWT.

- The required anchorage length of spliced bar was about 6-6.4 times the diameter of spliced bar, which is shorter than the existing non-proprietary sleeves. This indicates that the performance of GSW and GSWT is better than the existing non-proprietary sleeves. The tensile capacity of the spliced specimen was increased significantly with increasing diameter of rebar. Thus, the bearing capacity of grouted splice can be increased, and the length of grouted sleeve can be shortened by increasing the diameter of spliced bar in anchorage segment. 
- The tensile capacity of the specimen was mainly affected by the slope when the wedge length in the sleeve is less than $30 \mathrm{~mm}$ but was dominantly influenced by the length of the wedge when the wedge length is more than $30 \mathrm{~mm}$. The tensile capacity of specimen increased with the increase of the slope and the wedge length.

- Threads in GSWT do not help improve the tensile capacity because of the good performance of wedges compared to GSW under uniaxial tension but result in obvious improvement in the distribution of load carrying capacity of the sleeve as well as the bond strength and bearing capacity in non-wedge segment of GSWT.

\section{Acknowledgments}

The authors gratefully acknowledge the financial support from the Hubei Province Construction Science and Technology Plan Project (Grant No. 20171103), the Scientific and Technological Plan Project of Wuhan Urban and Rural Construction Commission (Grant No. 201812) and the Yellow Crane Meritocracy Plan (Urban Construction) of Wuhan (Grant No. 20161j0013).

\section{References}

[1] Yan QS, Chen TY, Xie ZY. Seismic experimental study on a precast concrete beam-column connection with grout sleeves. Eng Struct 2018;155:330-44.

[2] Breccolotti M, Gentile S, Tommasini M, Materazzi AL, Bonfigli MF, Pasqualini B, et al. Beam-column joints in continuous RC frames: Comparison between cast-in-situ and precast solutions. Eng Struct 2016;127:129-44.

[3] Parastesh H, Hajirasouliha I, Ramezani R. A new ductile moment-resisting connection for precast concrete frames in seismic regions: An experimental investigation. Eng Struct 2014;70:144-57.

[4] Guan DZ, Cheng J, Guo ZX, Ge HB. Development and seismic behavior of precast concrete beam-to-column connections. J Earthquake Eng 2016;22(2):234-56.

[5] Xiao JZ, Ding T, Zhang QT. Structural behavior of a new moment-resisting DfD concrete connection. Eng Struct 2017;132:1-13.

[6] Haber ZB, Saiidi MS, Sanders DH. Seismic performance of precast columns with mechanically spliced column-footing connections. Aci Struct J 2014;111(3):639-50.

[7] Ling JH, Abd Rahman AB, Ibrahim IS. Feasibility study of grouted splice connector under tensile load. Constr Build Mater 2014;50(1):530-39.

[8] Alias A, Sapawi F, Kusbiantoro A, Zubir MA, Abd Rahman AB. Performance of grouted splice 
sleeve connector under tensile load. J Mech Eng Sci (JMES) 2014;7:1094-102.

[9] Henin E, Morcous G. Non-proprietary bar splice sleeve for precast concrete construction. Eng Struct 2015;83:154-62.

[10] Zheng YF, Guo ZX, Liu JB, Chen XN, Xiao QD. Performance and confining mechanism of grouted deformed pipe splice under tensile load. Adv Struct Eng 2016;19(1):86-103.

[11] Kuang ZP, Zheng GY. Computational and experimental mechanical modelling of a composite grouted splice sleeve connector system. Mater 2018;11(306):1-12.

[12] Ameli MJ, Brown DN, Parks JE, Pantelides CP. Seismic column-to-footing connections using grouted splice sleeves. Aci Struct J 2016;113(5):1021-030.

[13] Ameli MJ, Parks JE, Brown DN, Pantelides CP. Seismic evaluation of grouted splice sleeve connections for reinforced precast concrete column-to-cap beam joints in accelerated bridge construction. PCI J 2015;60(2):80-103.

[14] Zheng YF, Guo ZX, Guan DZ, Zhang X. Parametric study on a novel grouted rolling pipe splice for precast concrete construction. Constr Build Mater 2018;166:452-63.

[15] Ling JH, Abd Rahman AB, Ibrahim IS, Hamid ZA. Tensile capacity of grouted splice sleeves. Eng Struct 2016;111:285-96.

[16] Einea A, Yamane T, Tadros MK. Grout-filled pipe splices for precast concrete construction. PCI J 1995;40(1):82-93.

[17] Ling JH, Abd Rahman AB, Ibrahim IS, Hamid ZA. Behaviour of grouted pipe splice under incremental tensile load. Constr Build Mater 2012;33:90-8.

[18] Aldin Hosseini SJ, Abd Rahman AB, Osman MH, Saim A, Adnan A. Bond behavior of spirally confined splice of deformed bars in grout. Constr Build Mater 2015;80:180-94.

[19] Alias A, Zubir MA, Shahid KA, Abd Rahman AB. Structural performance of grouted sleeve connectors with and without transverse reinforcement for precast concrete structure. Proc Eng 2013;53(7):116-23.

[20] Sayadi AA, Abd Rahman AB, Bin Jumaat MZ, Alengaram UJ, Ahmad S. The relationship between interlocking mechanism and bond strength in elastic and inelastic segment of splice sleeve. Constr Build Mater 2014;55:227-37.

[21] Untrauer RE, Henry RL. Influence of normal pressure on bond strength. ACI Struct J 1965;62(5):577-85.

[22] Huang Y, Zhu ZG, Naito CJ, Yi WJ. Tensile behavior of half grouted sleeve connections: 
Experimental study and analytical modeling. Constr Build Mater 2017;152:96-104.

[23] JG/T408-2013. Cementitious grout for coupler of rebar splicing. Beijing: Standards Press of China; 2013. (in Chinese).

[24]JGJ107-2016. Technical specification for mechanical splicing of steel reinforcing bars. Beijing: China Architecture \& Building Press; 2016. (in Chinese).

[25] Ashtiani MS, Dhakal RP, Scott AN. Post-yield bond behaviour of deformed bars in high-strength self-compacting concrete. Constr Build Mater 2013;44(7):236-48.

[26] Parks JE, Papulak T, Pantelides CP. Acoustic emission monitoring of grouted splice sleeve connectors and reinforced precast concrete bridge assemblies. Constr Build Mater 2016;122:537-47.

[27] Thompson MK, Jirsa JO, Breen JE, Klingner RE. Anchorage behaviour of headed reinforcement: literature review. Austin: University of Texas; 2002.

[28] JG/T398-2012. The grouting coupler for rebars splicing. Beijing: Standards Press of China; 2012. (in Chinese).

[29] ACI-318. Building code requirements for structural concrete and commentary. Farmington Hills, MI: American Concrete Institute; 2011.

[30] JGJ355-2015. Technical specification of grout sleeve splicing for rebars. Beijing: China Architecture \& Building Press; 2015. (in Chinese).

[31] BS8110-1: 1997. Structural Use of Concrete - Part 1: Code of Practice for Design and Construction. British Standards BSI; 1997.

[32] GB50017-2017. Code for design of steel structures. Beijing: China Planning Press; 2017. (in Chinese).

[33]Ling JH. Behaviour of grouted splice connections in precast concrete walls subjected to tensile, shear and flexural loads. Universiti Teknologi Malaysia; 2011. PhD.

[34] Zheng YF, Guo ZX, Cao J. Confinement mechanism and confining stress distribution of new grouting coupler for rebars splicing. Journal of Harbin Institute of Technology 2015;47(12):106-11. (in Chinese).

[35] Zheng YF. Research on rebar splicing system by GDPS grout-filled coupling sleeve. Southeast University; 2016. PhD. (in Chinese).

[36] Koushfar K, Abd. Rahman AB, Ahmad Y, Osman MH. Bond behavior of the reinforcement bar in glass fiber-reinforced polymer connector. Gradevinar 2014;66(4):301-10. 
[37] Cairns J, Plizzari GA. Towards a harmonised European bond test. Mater Struct 2003;36(8):498-506.

[38] Kim H. Bond Strength of mortar-filled steel pipe splices reflecting confining effect. J Asian Archit Build 2012;11(1):125-32.

[39] Sayadi AA, Abd Rahman AB, Sayadi A, Bahmani M, Shahryari L. Effective of elastic and inelastic zone on behavior of glass fiber reinforced polymer splice sleeve. Constr Build Mater 2015;80:38-47.

[40] ACI-116. Cement and concrete terminology ACI 116R-00 2000.

[41] Lin F, Wu XB. Mechanical performance and stress-strain relationships for grouted splices under tensile and cyclic loadings. Int J Concr Struct Mater 2016;10(4):435-450.

[42] Jansson PO. Evaluation of grout-filled mechanical splices for precast concrete construction. R-1512. Michigan: Michigan Department of Transportation MDOT; 2008.

[43] Coogler KL. Investigation of the behaviour of offset mechanical splices. University of Pittsburgh; 2006. 


\begin{tabular}{|c|c|c|c|}
\hline \multicolumn{4}{|c|}{ Nomenclature } \\
\hline$D_{S}$ & outer diameter of sleeve $(\mathrm{mm})$ & $f_{y}$ & yield strength of steel bar (MPa) \\
\hline$t_{b}$ & wall thickness of sleeve (mm) & $f_{u}$ & tensile strength of steel bar (MPa) \\
\hline$d_{n}$ & nominal bar diameter (mm) & $f_{t y}$ & yield strength of sleeve (MPa) \\
\hline$L$ & whole length of sleeve (mm) & $f_{t u}$ & tensile strength of sleeve (MPa) \\
\hline$L_{1}$ & wedge segment length of sleeve (mm) & $f_{\text {sty }}$ & specified yield strength of steel tube (MPa) \\
\hline$L_{2}$ & embedded length of spliced bar (mm) & $f_{\text {syk }}$ & specified yield strength of steel bar (MPa) \\
\hline$L_{3}$ & $\begin{array}{l}\text { non-wedge segment length of sleeve } \\
(\mathrm{mm})\end{array}$ & $f_{\text {stk }}$ & specified tensile strength of steel bar (MPa) \\
\hline$R_{S}$ & strength ratio & $f_{y s t}$ & yield strength of specimen (MPa) \\
\hline$R_{y}$ & yield ratio & $f_{\text {ust }}$ & ultimate tensile strength of specimen (MPa) \\
\hline$R_{d}$ & ductility ratio & $\delta_{y}$ & displacement of specimen at yield (mm) \\
\hline$R_{c}$ & reliability ratio & $f_{s d}$ & transverse tensile stress of sleeve (MPa) \\
\hline$E_{d}$ & elastic modulus of steel bar (MPa) & $\delta_{u}$ & displacement of specimen at failure (mm) \\
\hline$E_{m}$ & elastic modulus of sleeve (MPa) & $P_{y}$ & yield load of specimen $(\mathrm{kN})$ \\
\hline$f_{u g}$ & compressive strength of grout (MPa) & $P_{u}$ & ultimate load of specimen $(\mathrm{kN})$ \\
\hline$\varepsilon_{s l}$ & longitudinal strain of sleeve & $\beta$ & wedge slope $\left(^{\circ}\right)$ \\
\hline$\varepsilon_{s t}$ & circumferential strain of sleeve & $P_{w}$ & wedge segment bearing capacity $(\mathrm{kN})$ \\
\hline$\tau_{g}$ & $\begin{array}{l}\text { non-wedge segment bond stress at } \\
\text { sleeve-grout interface (MPa) }\end{array}$ & $P_{g}$ & non-wedge segment bearing capacity $(\mathrm{kN})$ \\
\hline$u_{n}$ & $\begin{array}{l}\text { average confinement stress acting on } \\
\text { grout }(\mathrm{MPa})\end{array}$ & $T_{s}$ & transverse tensile force of sleeve $(\mathrm{kN})$ \\
\hline$u_{g j}$ & $\begin{array}{l}\text { average confinement stress acting on } \\
\text { splice bar }(\mathrm{MPa})\end{array}$ & $P_{n}$ & bond force of grouted splice $(\mathrm{kN})$ \\
\hline$d_{t n}$ & $\begin{array}{l}\text { inner diameter of non-wedge segment in } \\
\text { sleeve }(\mathrm{mm})\end{array}$ & $F_{n}$ & confinement force acting on grout $(\mathrm{kN})$ \\
\hline$\alpha$ & reduction coefficient of bearing capacity & $u_{i}$ & $\begin{array}{l}\text { average bond strength at bar-grout interface } \\
(\mathrm{MPa})\end{array}$ \\
\hline$A_{m l}$ & inner surface area of sleeve $\left(\mathrm{mm}^{2}\right)$ & $P_{j}$ & $\begin{array}{l}\text { average ultimate load of specimen with rebar } \\
\text { fracture failure }(\mathrm{kN})\end{array}$ \\
\hline$A_{1}$ & $\begin{array}{l}\text { non-wedge segment inner surface area } \\
\left(\mathrm{mm}^{2}\right)\end{array}$ & $P_{c}$ & ultimate load of rebar in property test $(\mathrm{kN})$ \\
\hline$A_{2}$ & wedge segment inner surface area $\left(\mathrm{mm}^{2}\right)$ & $F_{b}$ & tensile capacity of spliced bar $(\mathrm{kN})$ \\
\hline$d_{m n}$ & inner diameter of sleeve end (mm) & $P_{u, p r e}$ & predicted tensile capacity of grouted splice $(\mathrm{kN})$ \\
\hline$A_{s}$ & cross-sectional area of sleeve $\left(\mathrm{mm}^{2}\right)$ & $P_{u, e x p}$ & $\begin{array}{l}\text { experimental tensile capacity of grouted splice } \\
(\mathrm{kN})\end{array}$ \\
\hline$h_{f}$ & welding foot length (mm) & $f_{w}$ & weld strength $(\mathrm{MPa})$ \\
\hline$h_{e}$ & effective foot length (mm) & $N$ & weld bearing capacity $(\mathrm{kN})$ \\
\hline$l_{w}$ & weld length (mm) & & \\
\hline
\end{tabular}




\section{Figures}

(a)

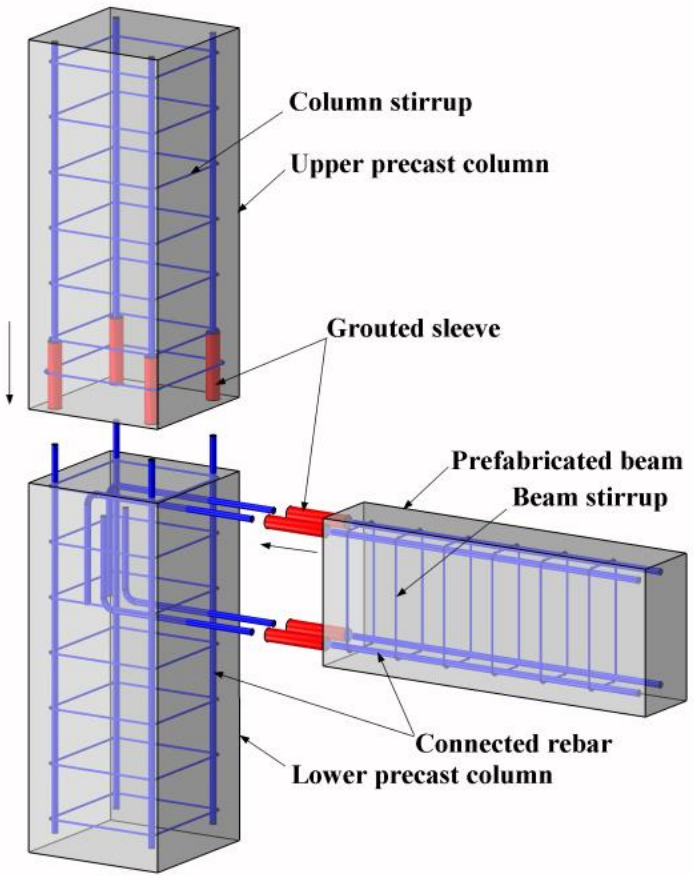

(b)

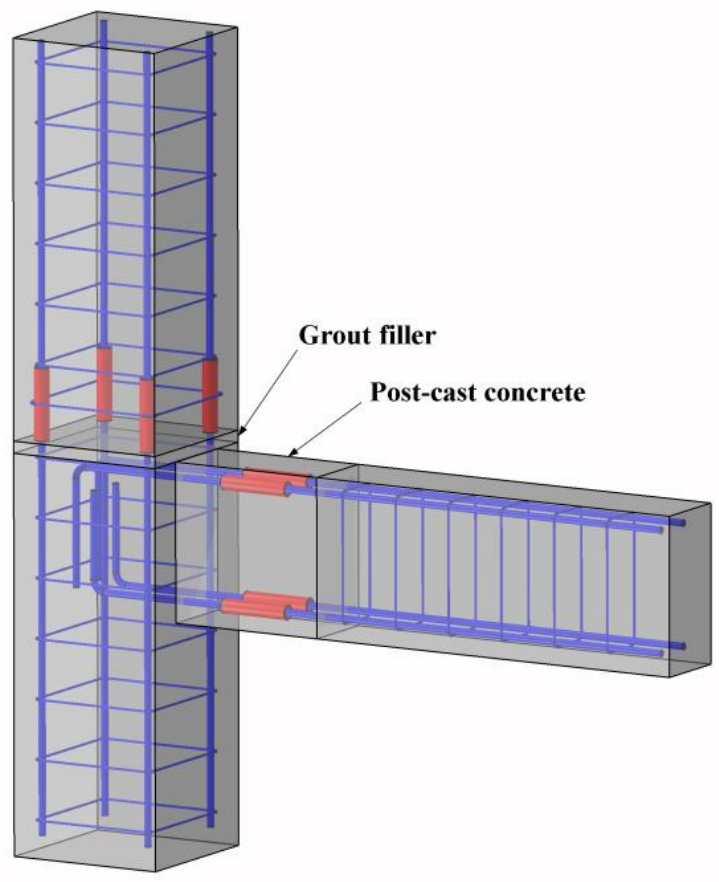

Fig. 1. Grouted sleeve connections used in precast beam-column joint: (a) site construction; (b) after construction on site.
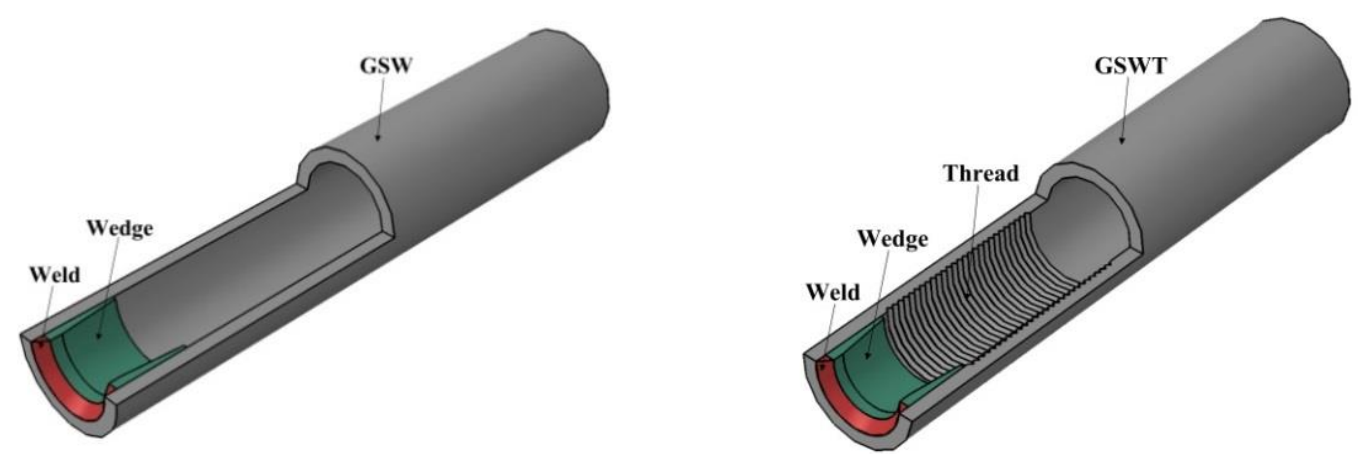

Fig. 2. Diagrams of the two types of sleeves, GSW and GSWT. 
(a)

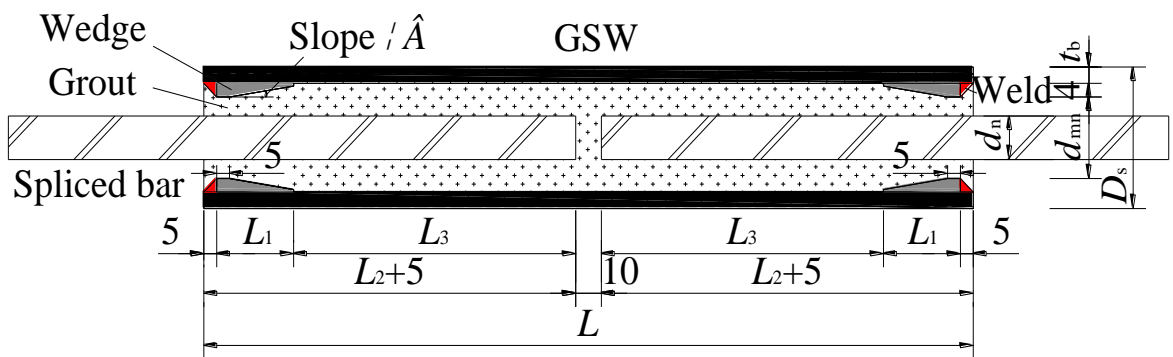

(b)

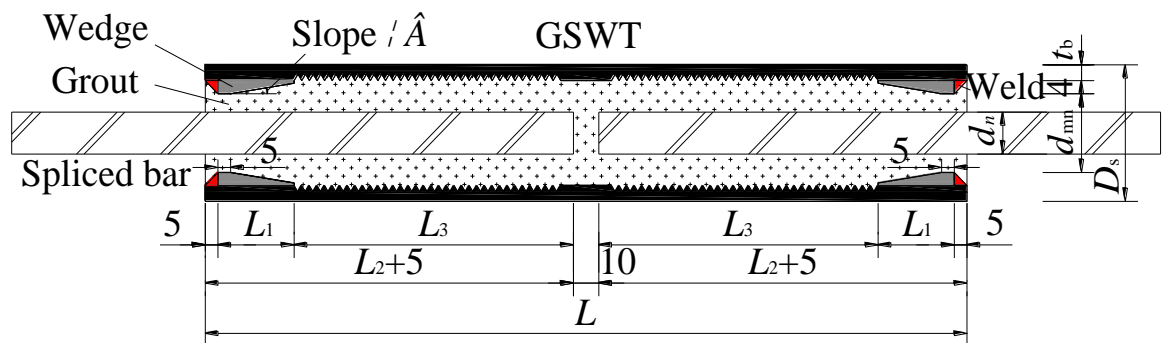

Fig. 3. Details of specimens: (a) specimen with GSW; (b) specimen with GSWT.
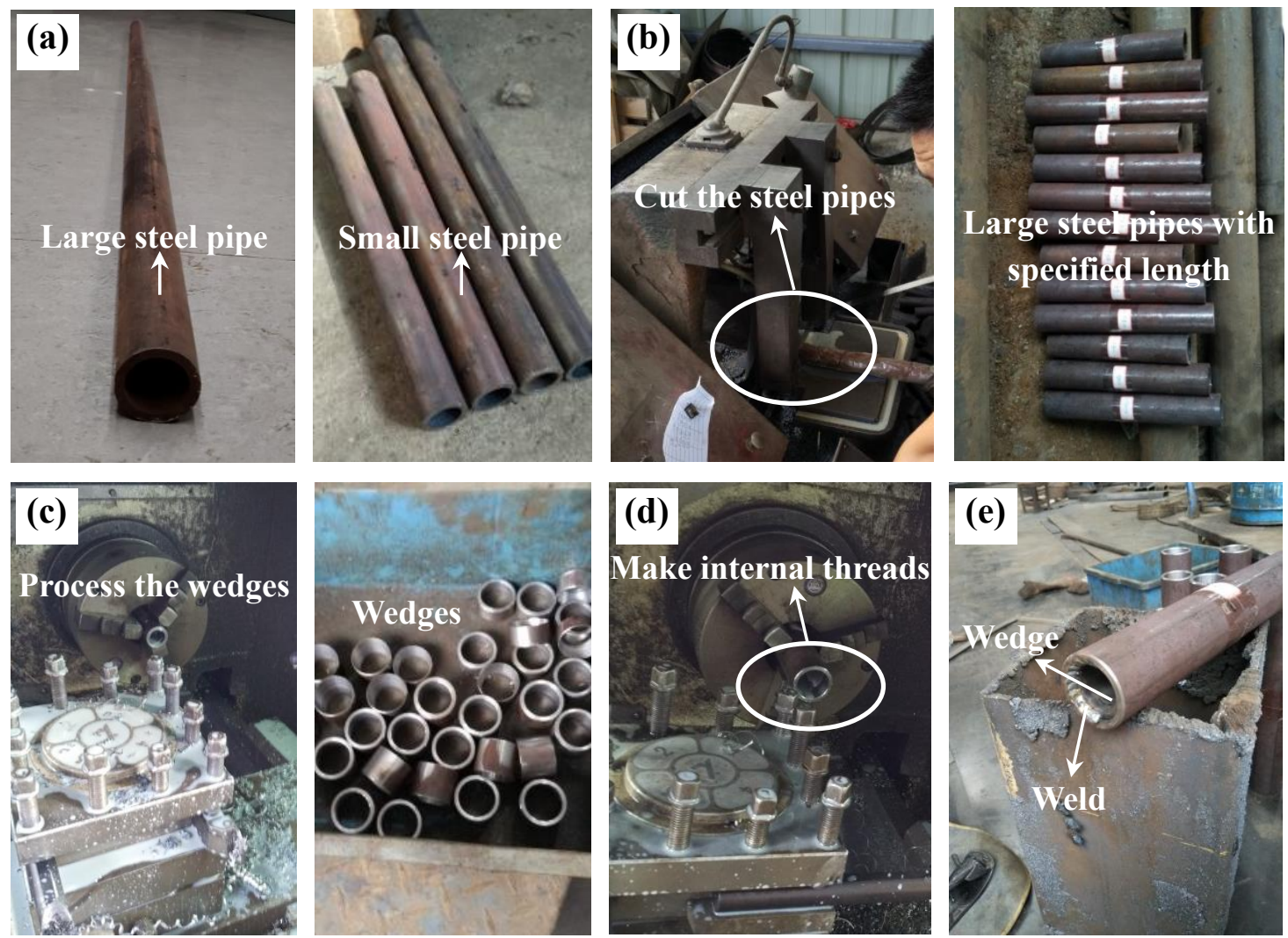

Fig. 4. Fabrication of the two kinds of grouted sleeves: (a) large and small steel pipes; (b) cut the steel pipes into a specified length; (c) process the wedges by using a numerical control machine; (d) make internal threads; (e) weld wedges. 

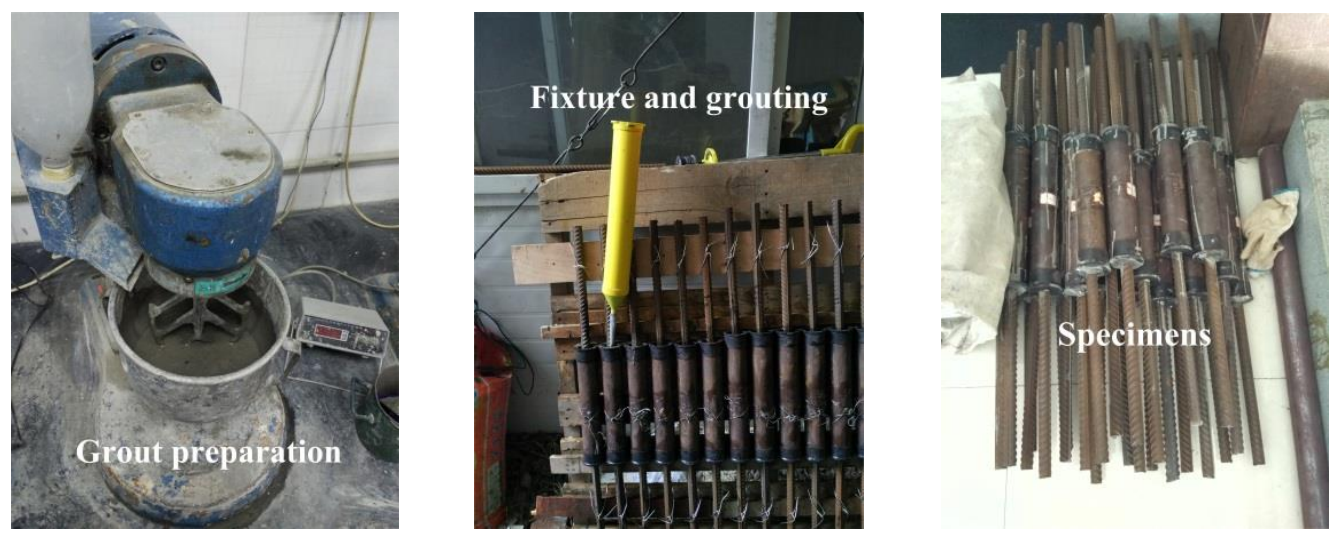

Fig. 5. Fabrication of specimens.
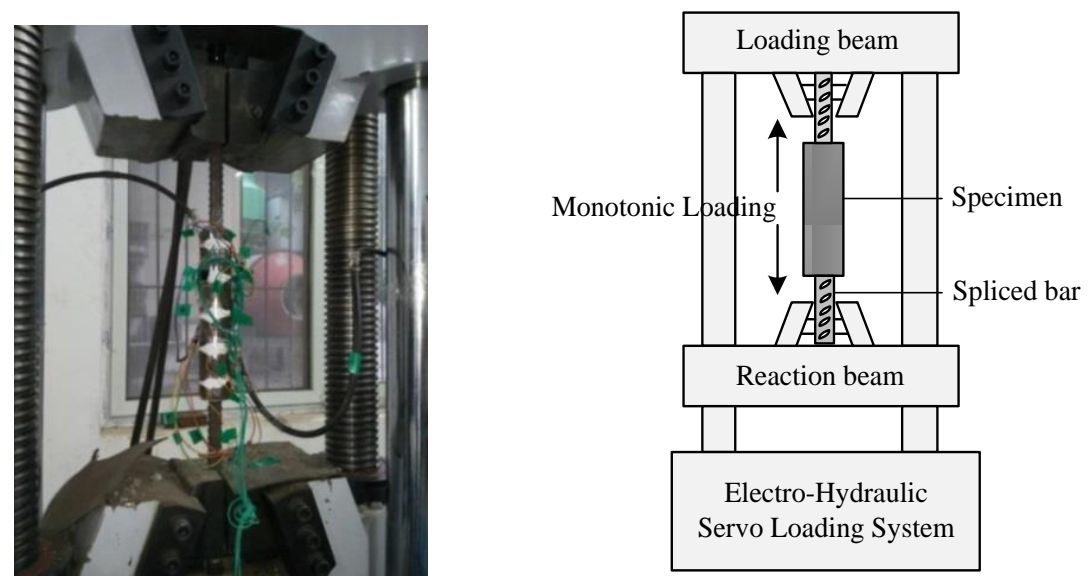

Fig. 6. Uniaxial tension test setup.

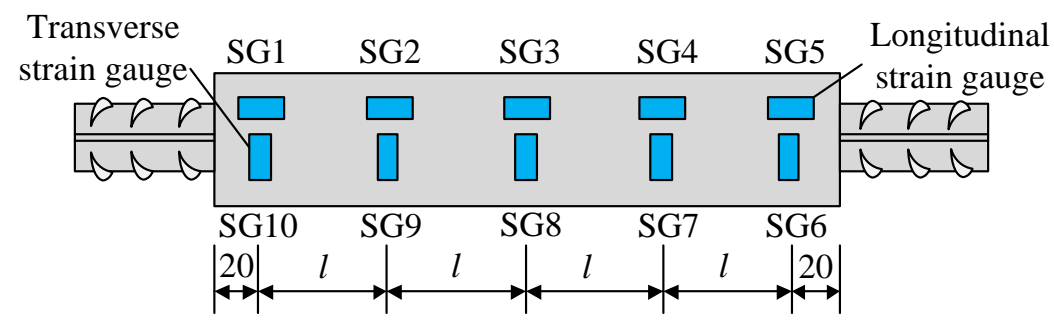

Fig. 7. Arrangement of strain gauges on specimens. 

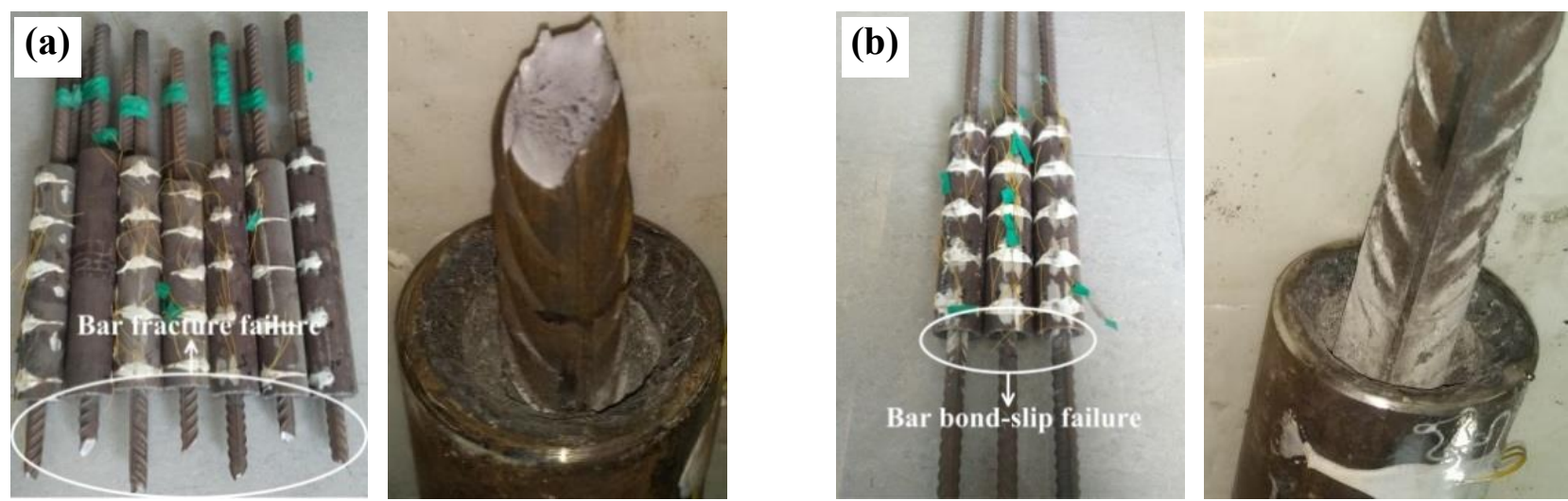

Fig. 8. Failure modes: (a) spliced bar fracture failure; (b) spliced bar bond-slip failure.

(a)
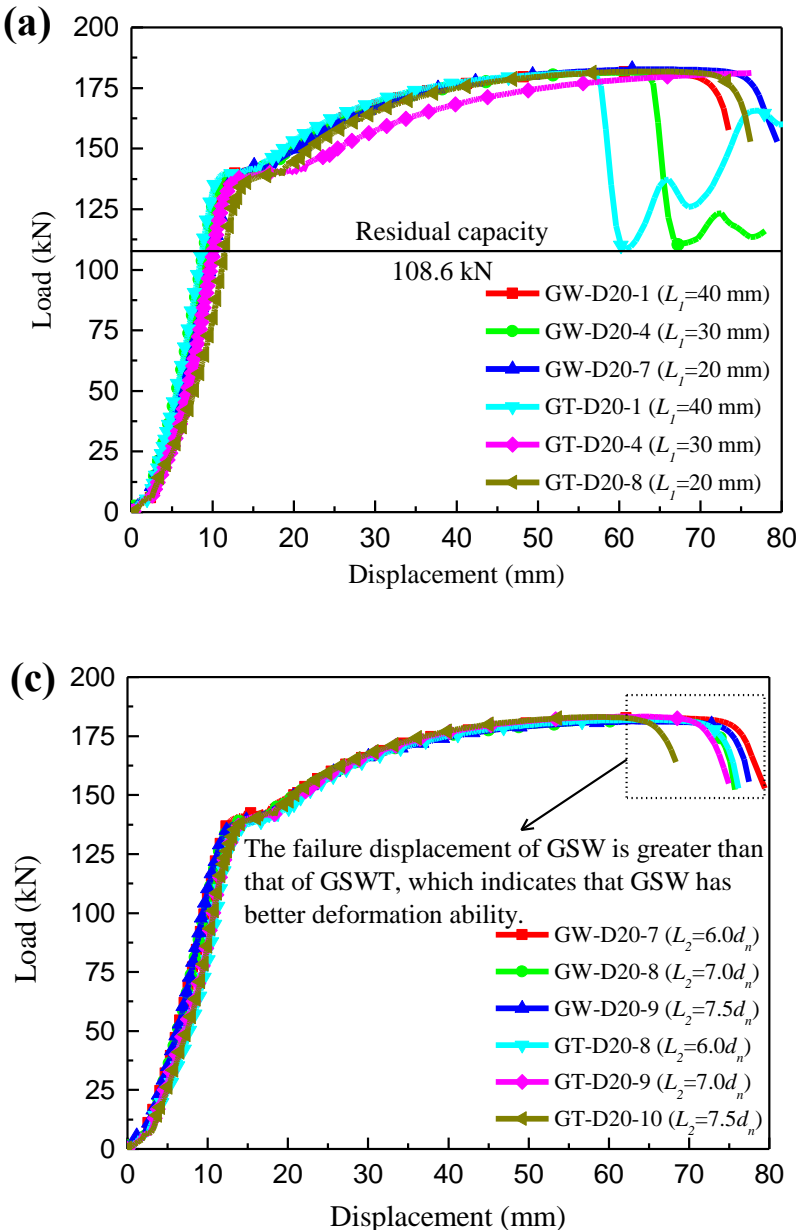

(b)

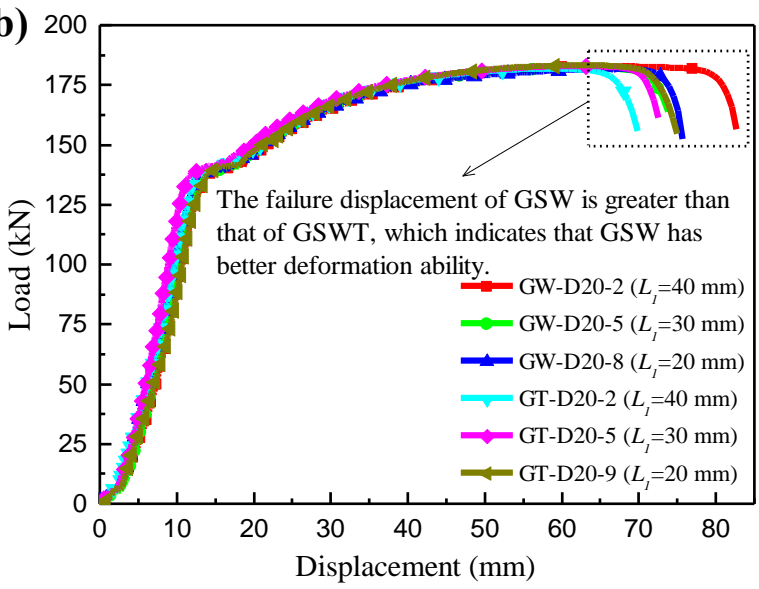

(d)

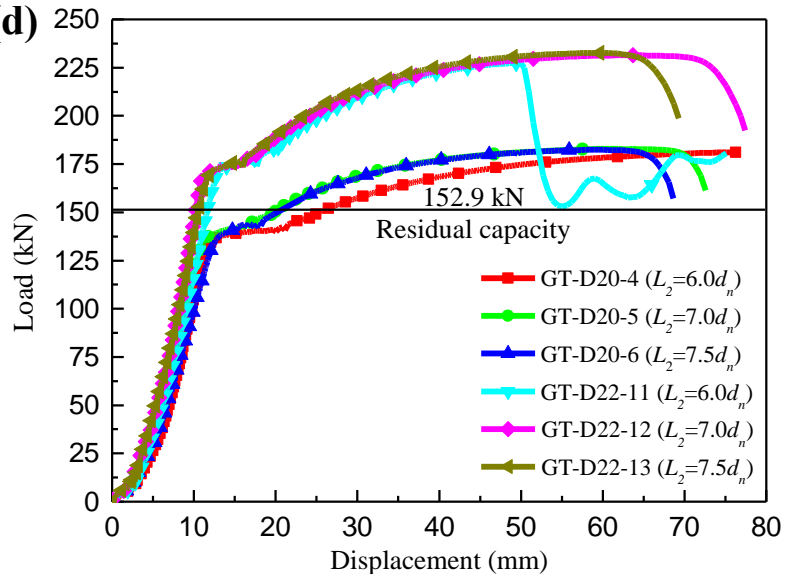

Fig. 9. Load-displacement curves of specimens: (a) with bar embedment length of $6 d_{n}$ but various wedge lengths; (b) with bar embedment length of $7 d_{n}$ but various wedge lengths; (c) with wedge length of $20 \mathrm{~mm}$ but various spliced bar diameters; (d) with wedge length of $30 \mathrm{~mm}$ but different spliced bar diameters. 

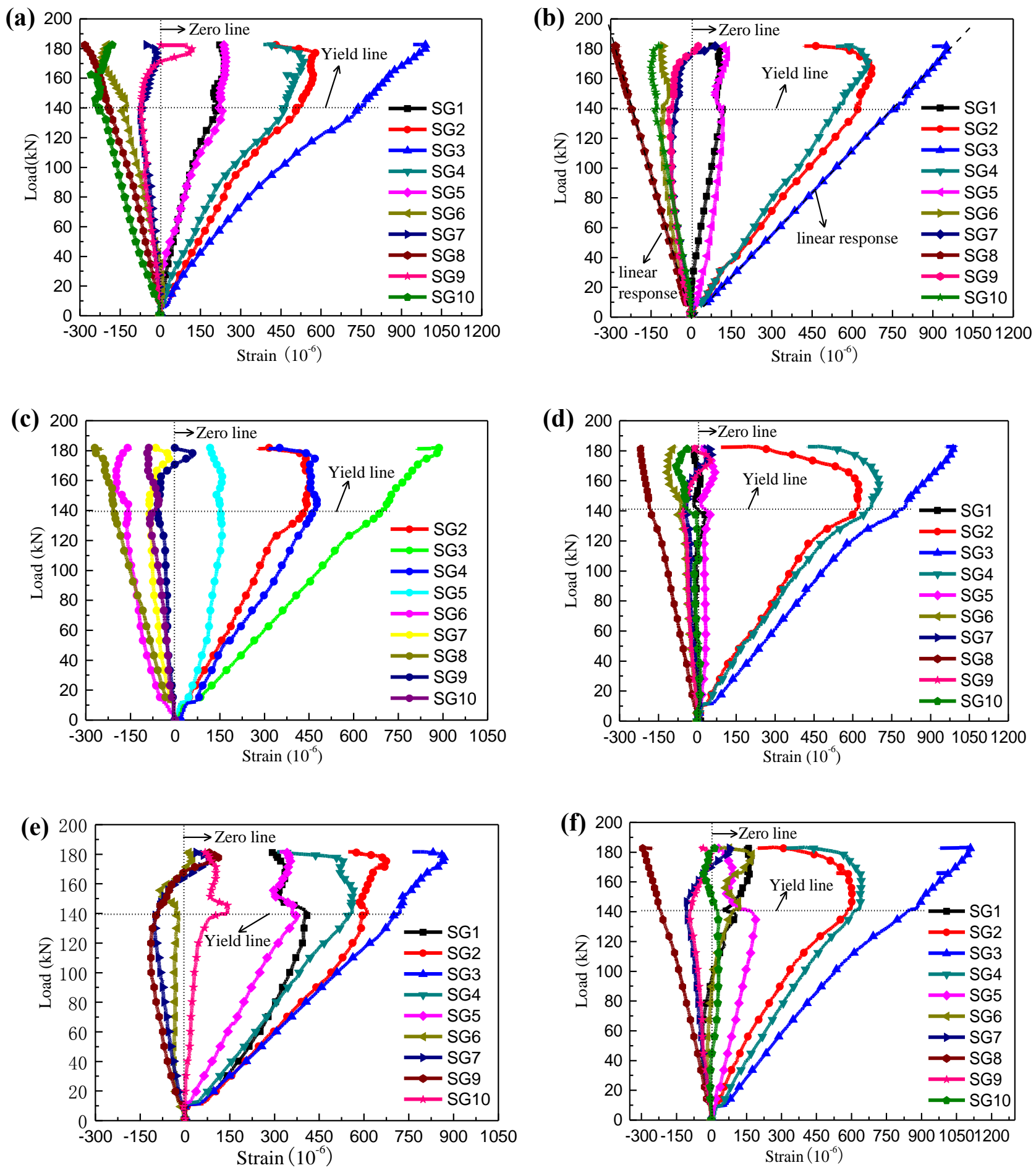

Fig. 10. Load-strain response of specimens: (a) specimen GW-D20-2 (wedge length $40 \mathrm{~mm}$ ); (b) specimen GT-D20-2 (wedge length $40 \mathrm{~mm}$ ); (c) specimen GW-D20-5 (wedge length $30 \mathrm{~mm}$ ); (d) specimen GT-D20-5 (wedge length $30 \mathrm{~mm}$ ); (e) specimen GW-D20-8 (wedge length $20 \mathrm{~mm}$ ); (f) specimen GT-D20-9 (wedge length $20 \mathrm{~mm}$ ). 

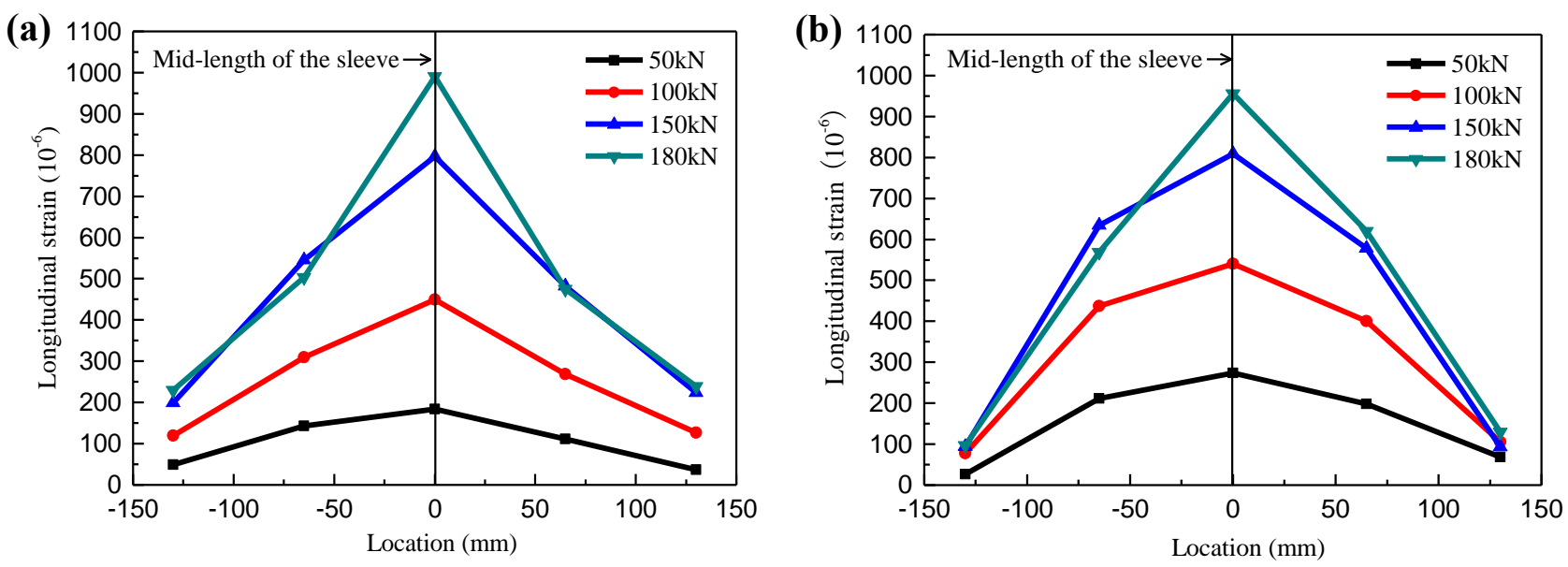

Fig. 11. Longitudinal strain distribution: (a) specimen GW-D20-2; (b) specimen GT-D20-2.
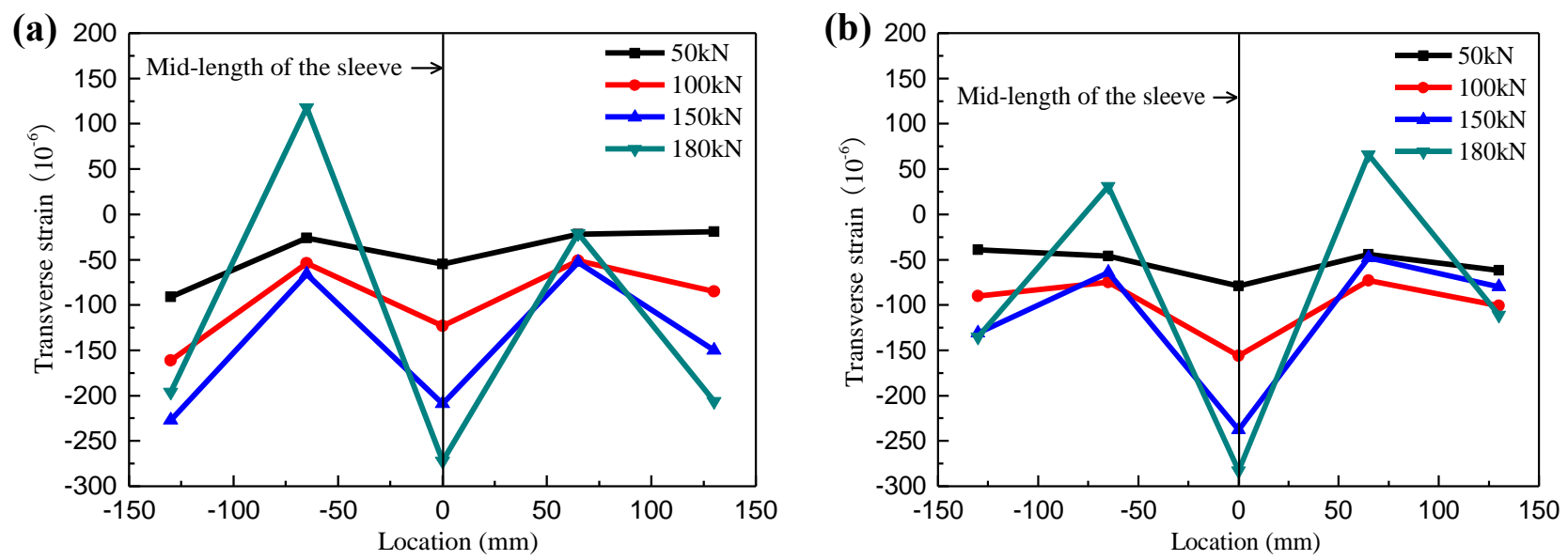

Fig. 12. Transverse strain distribution: (a) specimen GW-D20-2; (b) specimen GT-D20-2.

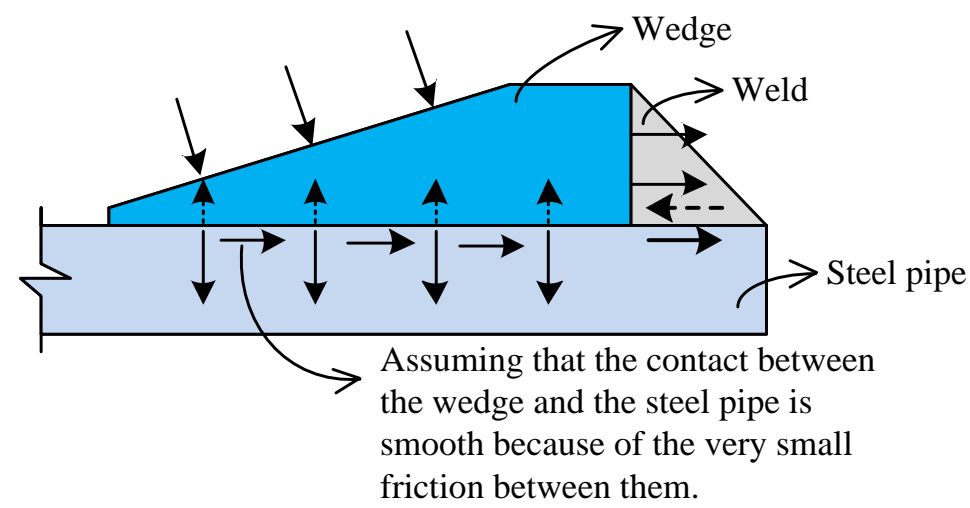

Fig. 13. Schematic diagram of load transfer from the weld to the sleeve. 


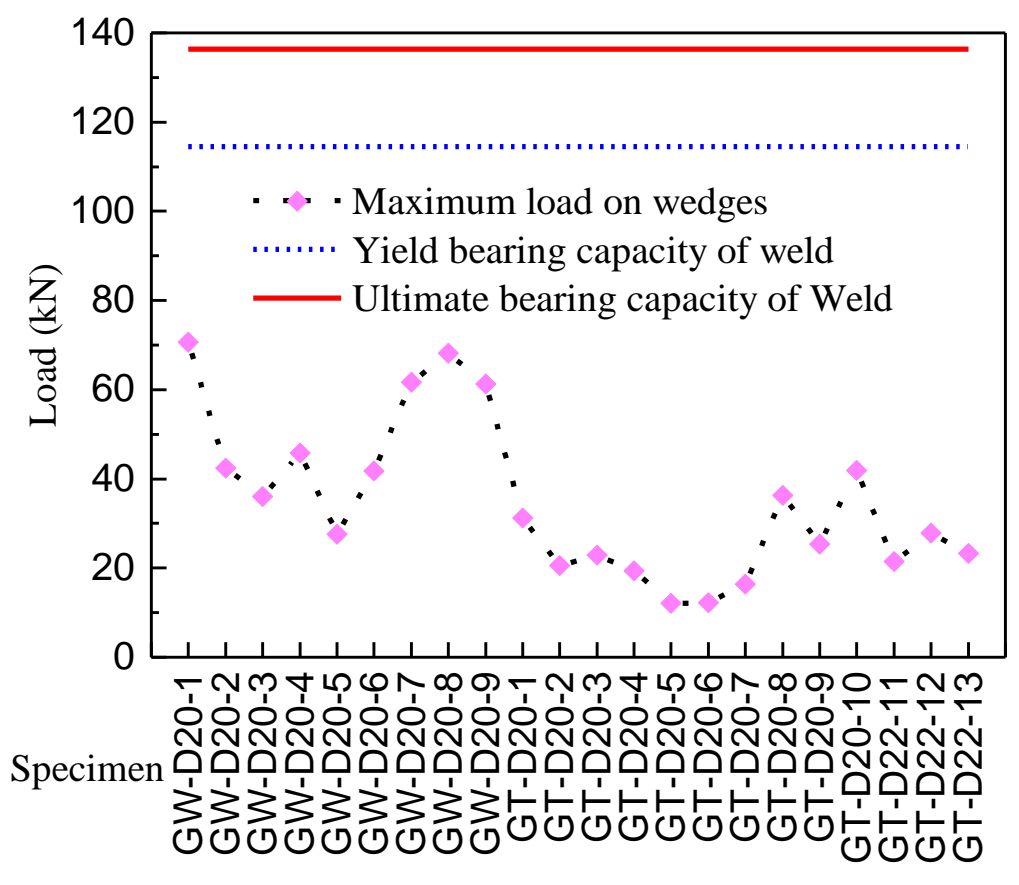

Fig. 14. Load bearing capacity of the weld within the specimens.

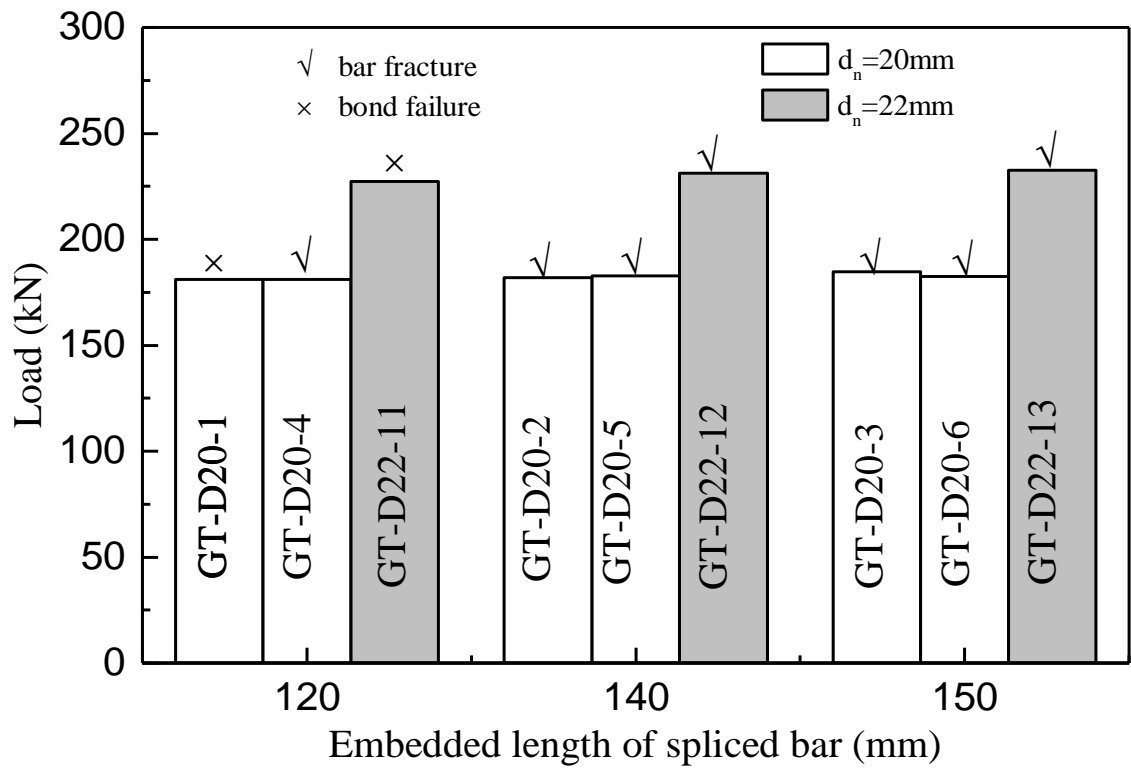

Fig. 15. Comparison of load bearing capacity of sleeves with various embedded lengths. 


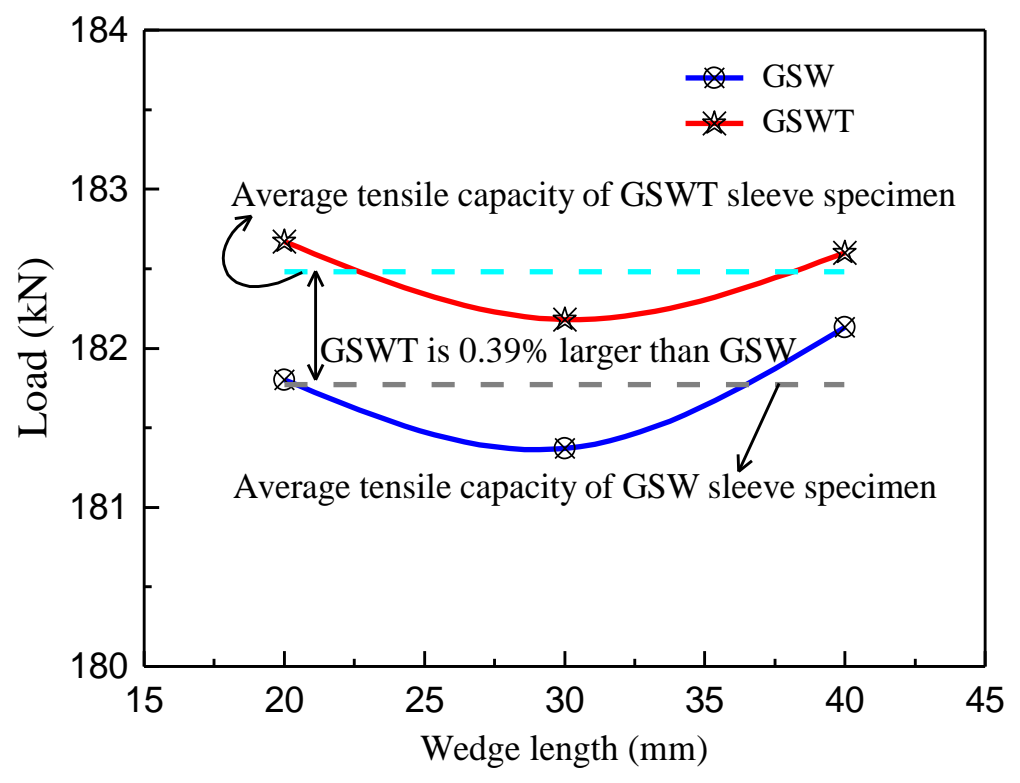

Fig. 16. Comparison of ultimate capacity of sleeves with various wedge lengths. 
The wedging action of the ribs on The wedging action of the wedge the spliced bar transmits the pulling force to the grout.

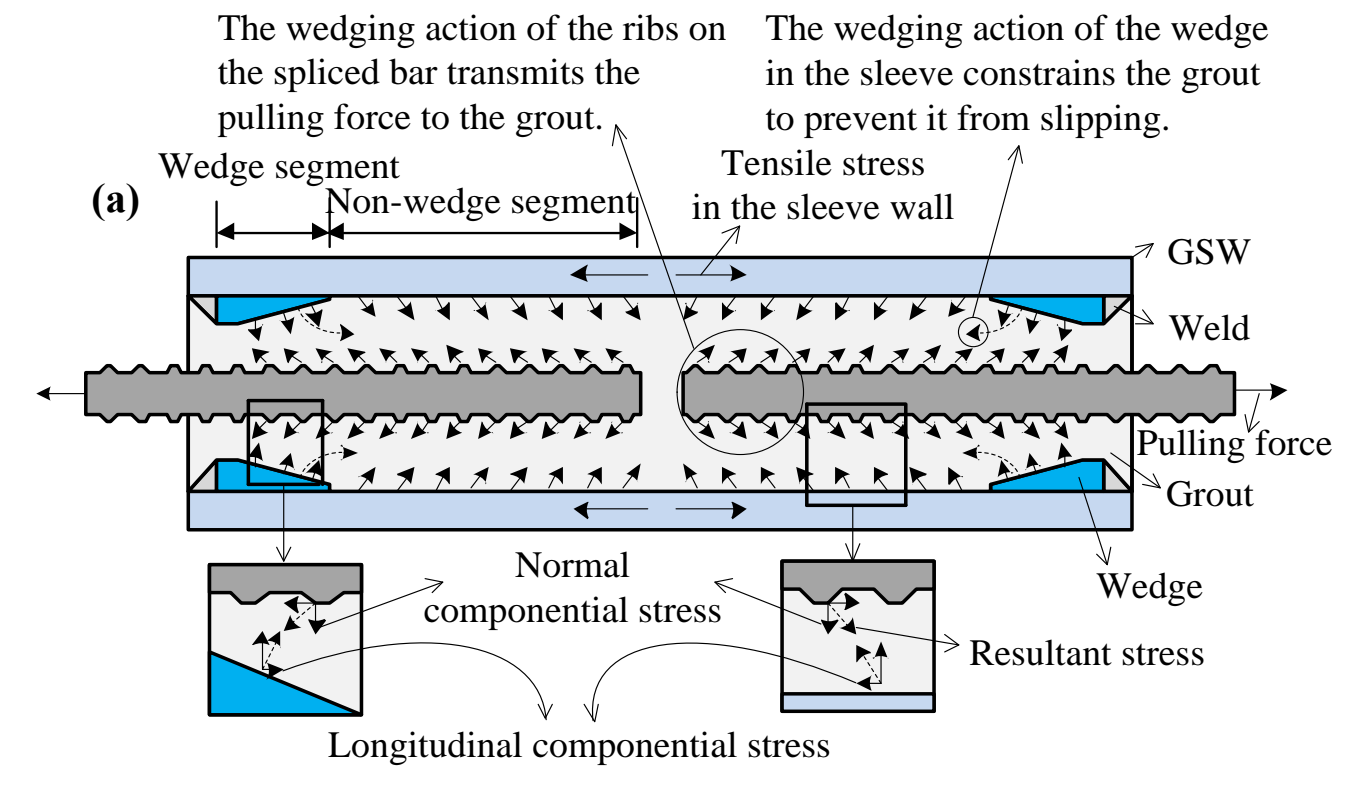
in the sleeve constrains the grout to prevent it from slipping.

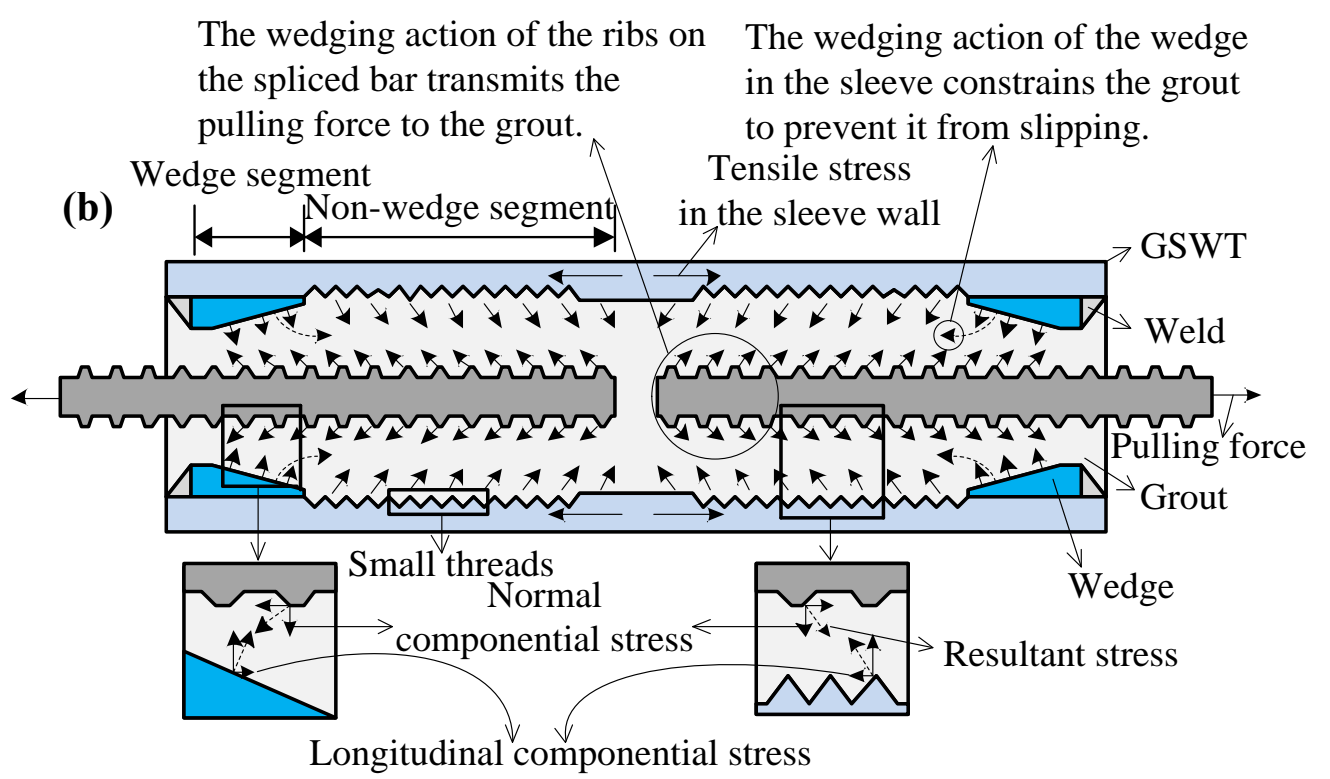

Fig. 17. Schematic diagram of mechanism of force transfer within the splices: (a) GSW; (b) GSWT. 


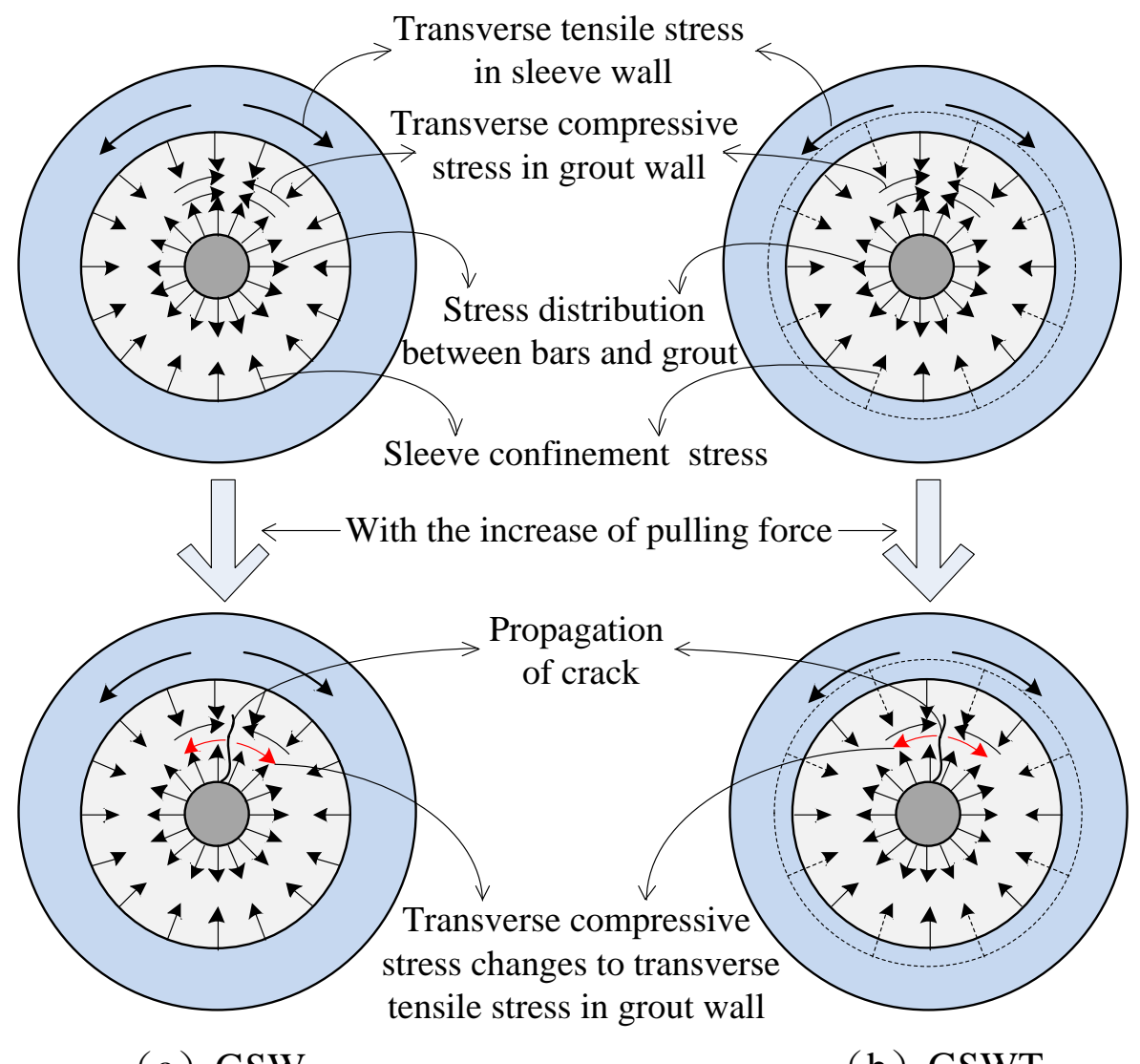

(a) GSW

(b) GSWT

Fig. 18. Distribution of confinement stress in the sleeves.

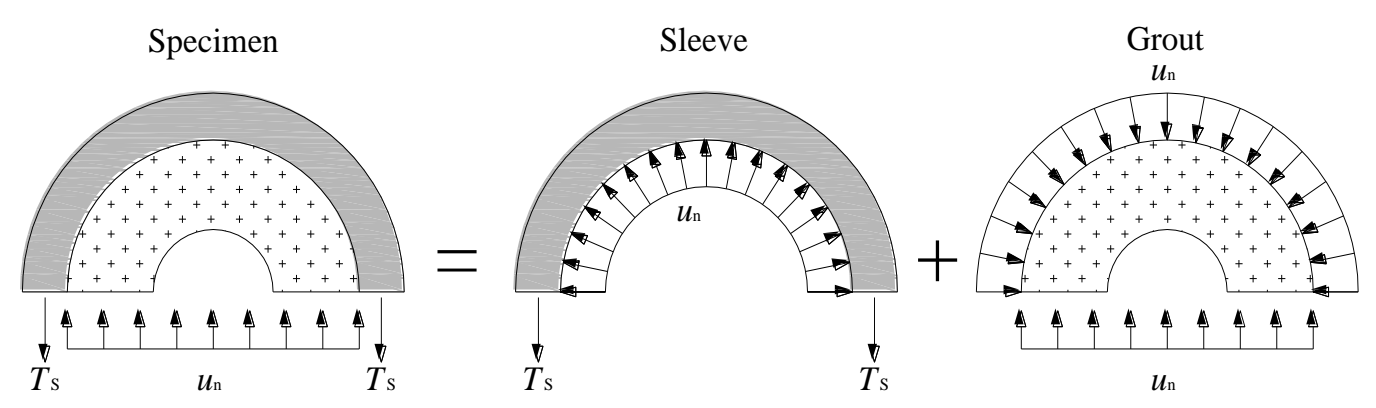

Fig. 19. Equilibrium relationship for a grouted splice specimen [16]. 


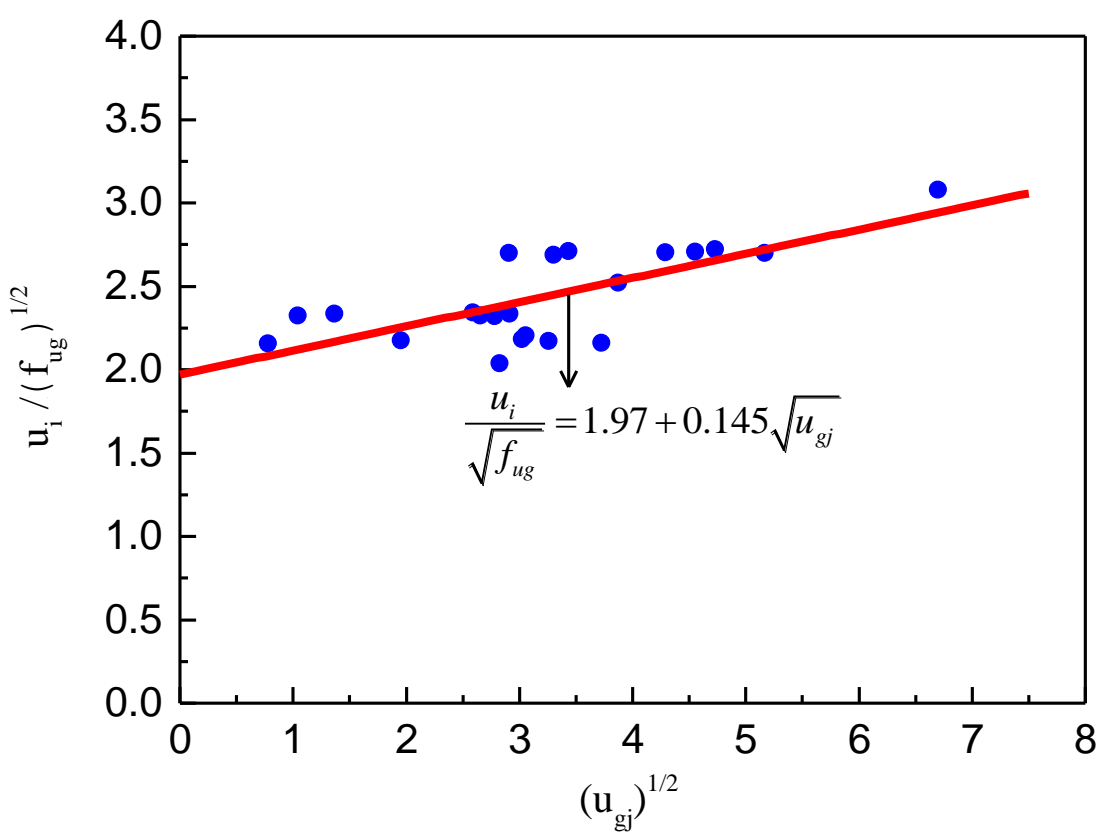

Fig. 20. Relationship between $u_{i} / \sqrt{f_{u g}}$ and $\sqrt{u_{g j}}$.

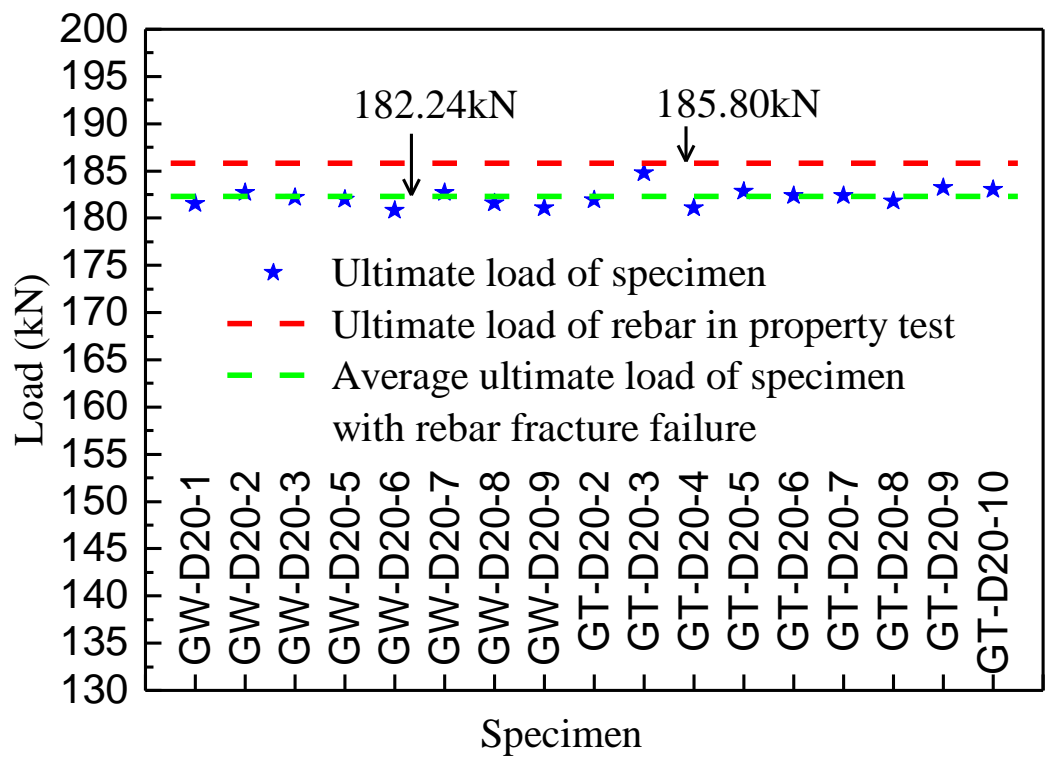

Fig. 21. Comparison of bearing capacity between specimen and steel bar. 

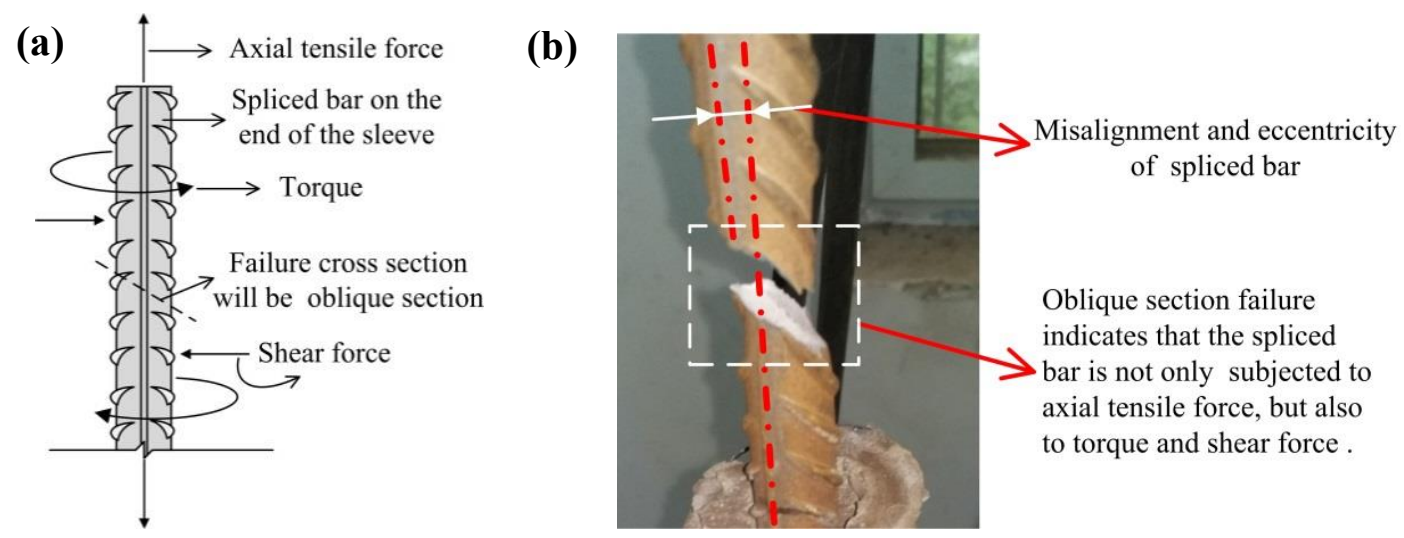

Fig. 22. Failure of spliced bar at the end of sleeve: (a) force diagram of spliced bar at the end of sleeve; (b) bar fracture failure on the test machine.

(a)

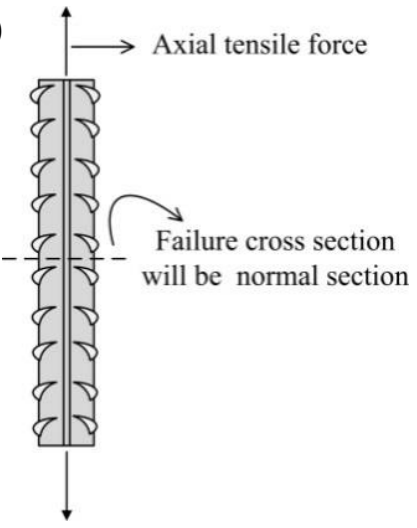

(b)

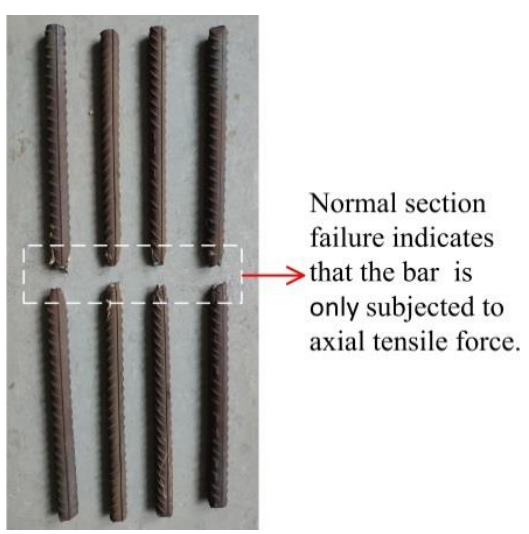

Fig. 23. Failure of a single bar in the material property test: (a) force diagram of steel bar; (b) bar fracture failure. 


\section{Tables}

Table 1 Properties of low alloy seamless steel pipes

\begin{tabular}{cccccc}
\hline $\begin{array}{c}\text { Outer diameter, } \\
D_{S}(\mathrm{~mm})\end{array}$ & $\begin{array}{c}\text { Wall thickness, } \\
t_{b}(\mathrm{~mm})\end{array}$ & $\begin{array}{c}\text { Yield strength, } \\
f_{t y}(\mathrm{MPa})\end{array}$ & $\begin{array}{c}\text { Tensile strength, } \\
f_{t u}(\mathrm{MPa})\end{array}$ & $\begin{array}{c}\text { Elastic modulus, } \\
E_{m}(\mathrm{MPa})\end{array}$ & $\begin{array}{c}\text { Elongation } \\
\text { rate }(\%)\end{array}$ \\
\hline 40 & 5 & 396 & 508 & $2.06 \times 10^{5}$ & 21.2 \\
51 & 6 & 399 & 512 & $2.06 \times 10^{5}$ & 21.7 \\
\hline
\end{tabular}

Table 2 Properties of steel bars

\begin{tabular}{ccccc}
\hline Diameter, $d_{n}(\mathrm{~mm})$ & $\begin{array}{c}\text { Yield strength, } \\
f_{y}(\mathrm{MPa})\end{array}$ & $\begin{array}{c}\text { Tensile strength, } \\
f_{u}(\mathrm{MPa})\end{array}$ & $\begin{array}{c}\text { Elastic modulus, } \\
E_{d}(\mathrm{MPa})\end{array}$ & Elongation rate (\%) \\
\hline 20 & 460 & 591 & $2.0 \times 10^{5}$ & 21.8 \\
22 & 463 & 614 & $2.0 \times 10^{5}$ & 22.0 \\
\hline
\end{tabular}


Table 3 Details of grouted sleeve specimens

\begin{tabular}{|c|c|c|c|c|c|c|}
\hline Specimen & Type of sleeve & $d_{n}(\mathrm{~mm})$ & $L(\mathrm{~mm})$ & $L_{1}(\mathrm{~mm})$ & $L_{2}(\mathrm{~mm})$ & $L_{3}(\mathrm{~mm})$ \\
\hline GW-D20-1 & & 20 & 260 & 40 & $120\left(6.0 d_{n}\right)$ & 80 \\
\hline GW-D20-2 & & 20 & 300 & 40 & $140\left(7.0 d_{n}\right)$ & 100 \\
\hline GW-D20-3 & & 20 & 320 & 40 & $150\left(7.5 d_{n}\right)$ & 110 \\
\hline GW-D20-4 & & 20 & 260 & 30 & $120\left(6.0 d_{n}\right)$ & 90 \\
\hline GW-D20-5 & GSW & 20 & 300 & 30 & $140\left(7.0 d_{n}\right)$ & 110 \\
\hline GW-D20-6 & & 20 & 320 & 30 & $150\left(7.5 d_{n}\right)$ & 120 \\
\hline GW-D20-7 & & 20 & 260 & 20 & $120\left(6.0 d_{n}\right)$ & 100 \\
\hline GW-D20-8 & & 20 & 300 & 20 & $140\left(7.0 d_{n}\right)$ & 120 \\
\hline GW-D20-9 & & 20 & 320 & 20 & $150\left(7.5 d_{n}\right)$ & 130 \\
\hline GT-D20-1 & & 20 & 260 & 40 & $120\left(6.0 d_{n}\right)$ & 80 \\
\hline GT-D20-2 & & 20 & 300 & 40 & $140\left(7.0 d_{n}\right)$ & 100 \\
\hline GT-D20-3 & & 20 & 320 & 40 & $150\left(7.5 d_{n}\right)$ & 110 \\
\hline GT-D20-4 & & 20 & 260 & 30 & $120\left(6.0 d_{n}\right)$ & 90 \\
\hline GT-D20-5 & & 20 & 300 & 30 & $140\left(7.0 d_{n}\right)$ & 110 \\
\hline GT-D20-6 & & 20 & 320 & 30 & $150\left(7.5 d_{n}\right)$ & 120 \\
\hline GT-D20-7 & GSWT & 20 & 340 & 30 & $160\left(8.0 d_{n}\right)$ & 130 \\
\hline GT-D20-8 & & 20 & 260 & 20 & $120\left(6.0 d_{n}\right)$ & 100 \\
\hline GT-D20-9 & & 20 & 300 & 20 & $140\left(7.0 d_{n}\right)$ & 120 \\
\hline GT-D20-10 & & 20 & 320 & 20 & $150\left(7.5 d_{n}\right)$ & 130 \\
\hline GT-D22-11 & & 22 & 260 & 30 & $120\left(5.5 d_{n}\right)$ & 90 \\
\hline GT-D22-12 & & 22 & 300 & 30 & $140\left(6.4 d_{n}\right)$ & 110 \\
\hline GT-D22-13 & & 22 & 320 & 30 & $150\left(6.8 d_{n}\right)$ & 120 \\
\hline
\end{tabular}


Table 4 Summary of test results

\begin{tabular}{|c|c|c|c|c|c|c|c|c|}
\hline Specimen & $\begin{array}{c}\text { Yield } \\
\text { load, } P_{y} \\
(\mathrm{kN})\end{array}$ & $\begin{array}{l}\text { Ultimate } \\
\text { load, } P_{u} \\
(\mathrm{kN})\end{array}$ & $\begin{array}{l}\text { Ultimate bond } \\
\text { strength, } \tau_{m} \\
(\mathrm{MPa})\end{array}$ & $\begin{array}{l}\text { Yield } \\
\text { ratio } \\
\left(R_{y}\right)\end{array}$ & $\begin{array}{c}\text { Strength } \\
\text { ratio } \\
\left(R_{S}\right)\end{array}$ & $\begin{array}{c}\text { Ductility } \\
\text { ratio } \\
\left(R_{d}\right)\end{array}$ & $f_{\text {ust }} / f_{\text {stk }}$ & $\begin{array}{l}\text { Failure } \\
\text { mode }^{\mathrm{a}}\end{array}$ \\
\hline GW-D20-1 & 139.08 & 181.5 & 24.08 & 1.11 & 1.45 & 4.79 & 1.07 & Fracture \\
\hline GW-D20-2 & 140.25 & 182.7 & 20.78 & 1.12 & 1.45 & 5.20 & 1.08 & Fracture \\
\hline GW-D20-3 & 140.18 & 182.2 & 19.34 & 1.12 & 1.45 & 5.21 & 1.07 & Fracture \\
\hline GW-D20-4 & 139.98 & 181.3 & 24.06 & 1.11 & 1.44 & 4.06 & 1.07 & Bond-slip \\
\hline GW-D20-5 & 139.69 & 182.0 & 20.70 & 1.11 & 1.45 & 4.59 & 1.07 & Fracture \\
\hline GW-D20-6 & 139.47 & 180.8 & 19.19 & 1.11 & 1.44 & 5.14 & 1.07 & Fracture \\
\hline GW-D20-7 & 142.12 & 182.7 & 24.24 & 1.13 & 1.45 & 5.33 & 1.08 & Fracture \\
\hline GW-D20-8 & 139.41 & 181.6 & 20.66 & 1.11 & 1.45 & 5.12 & 1.07 & Fracture \\
\hline GW-D20-9 & 138.82 & 181.1 & 19.23 & 1.10 & 1.44 & 5.36 & 1.07 & Fracture \\
\hline GT-D20-1 & 139.41 & 181.1 & 24.03 & 1.11 & 1.44 & 4.95 & 1.07 & Bond-slip \\
\hline GT-D20-2 & 139.31 & 181.9 & 20.69 & 1.11 & 1.45 & 5.10 & 1.07 & Fracture \\
\hline GT-D20-3 & 141.47 & 184.8 & 19.62 & 1.13 & 1.47 & 5.31 & 1.09 & Fracture \\
\hline GT-D20-4 & 140.70 & 181.1 & 24.03 & 1.12 & 1.44 & 4.29 & 1.07 & Fracture \\
\hline GT-D20-5 & 141.09 & 182.8 & 20.79 & 1.12 & 1.46 & 4.90 & 1.08 & Fracture \\
\hline GT-D20-6 & 140.60 & 182.4 & 19.36 & 1.12 & 1.45 & 4.67 & 1.08 & Fracture \\
\hline GT-D20-7 & 139.86 & 182.4 & 18.15 & 1.11 & 1.45 & 4.76 & 1.08 & Fracture \\
\hline GT-D20-8 & 138.96 & 181.8 & 24.12 & 1.11 & 1.45 & 4.59 & 1.07 & Fracture \\
\hline GT-D20-9 & 140.82 & 183.2 & 20.84 & 1.12 & 1.46 & 4.77 & 1.08 & Fracture \\
\hline GT-D20-10 & 139.10 & 183.0 & 19.43 & 1.11 & 1.46 & 4.56 & 1.08 & Fracture \\
\hline GT-D22-11 & 173.91 & 227.3 & 27.42 & 1.14 & 1.50 & 3.40 & 1.11 & Bond-slip \\
\hline GT-D22-12 & 171.37 & 231.3 & 23.92 & 1.13 & 1.52 & 6.42 & 1.13 & Fracture \\
\hline GT-D22-13 & 173.45 & 232.6 & 22.45 & 1.14 & 1.53 & 5.09 & 1.13 & Fracture \\
\hline
\end{tabular}

a "Fracture" represents spliced bar fracture, "Bond-slip" represents spliced bar bond-slip failure. 
Table 5 Strength grades of splice

\begin{tabular}{cccc}
\hline Strength grade & \multicolumn{1}{c}{ I } & II & III \\
\hline Ultimate tensile strength & $f_{\text {ust }} \geq f_{\text {stk }}$ (fracture of spliced bar) & \multirow{2}{*}{$f_{\text {ust }} \geq f_{\text {stk }}$} & $f_{\text {ust }} \geq 1.25 f_{\text {syk }}$ \\
\cline { 2 - 3 }$\left(f_{\text {ust }}\right)$ & $f_{\text {ust }} \geq 1.1 f_{\text {stk }}$ (connector damage) & & \\
\hline
\end{tabular}

Table 6 Bearing capacity of wedge segment and non-wedge segment of GSW

\begin{tabular}{cccccccc}
\hline Specimen & $\varepsilon_{s l}\left(10^{-6}\right)$ & $P_{u}(\mathrm{kN})$ & $P_{w}(\mathrm{kN})$ & $P_{g}(\mathrm{kN})$ & $P_{w} / P_{g}$ & $P_{w} / P_{u}$ & $\tau_{g}(\mathrm{MPa})$ \\
\hline GW-D20-1 & 370.0 & 181.5 & 64.65 & 116.85 & 0.55 & 0.36 & 11.77 \\
GW-D20-2 & 235.0 & 182.7 & 41.06 & 141.64 & 0.29 & 0.22 & 11.41 \\
GW-D20-3 & 163.0 & 182.2 & 28.48 & 153.72 & 0.19 & 0.16 & 11.26 \\
GW-D20-4 & 203.5 & 181.3 & 35.56 & 145.74 & 0.24 & 0.20 & 13.05 \\
GW-D20-5 & 115.0 & 182.0 & 20.09 & 161.91 & 0.12 & 0.11 & 11.86 \\
GW-D20-6 & 215.0 & 180.8 & 37.57 & 143.23 & 0.26 & 0.21 & 9.62 \\
GW-D20-7 & 280.5 & 182.7 & 49.01 & 133.69 & 0.37 & 0.27 & 10.77 \\
GW-D20-8 & 310.0 & 181.6 & 54.17 & 127.43 & 0.43 & 0.30 & 8.56 \\
GW-D20-9 & 261.0 & 181.1 & 45.60 & 135.50 & 0.34 & 0.25 & 8.40 \\
Minimum & & & 20.09 & 116.85 & 0.12 & 0.11 & 8.40 \\
Maximum & & & 64.65 & 161.91 & 0.55 & 0.36 & 13.05 \\
Average & & & 41.80 & 139.97 & 0.31 & 0.28 & 10.75 \\
\hline
\end{tabular}

Table 7 Bearing capacity of wedge segment and non-wedge segment of GSWT

\begin{tabular}{cccccccc}
\hline Specimen & $\varepsilon_{s l}\left(10^{-6}\right)$ & $P_{u}(\mathrm{kN})$ & $P_{w}(\mathrm{kN})$ & $P_{g}(\mathrm{kN})$ & $P_{w} / P_{g}$ & $P_{w} / P_{u}$ & $\tau_{g}(\mathrm{MPa})$ \\
\hline GT-D20-1 & 30.0 & 181.1 & 5.24 & 175.86 & 0.03 & 0.03 & 17.71 \\
GT-D20-2 & 99.0 & 181.9 & 17.30 & 164.60 & 0.11 & 0.10 & 13.26 \\
GT-D20-3 & 44.0 & 184.8 & 7.69 & 177.11 & 0.04 & 0.04 & 12.98 \\
GT-D20-4 & 18.5 & 181.1 & 3.23 & 177.87 & 0.02 & 0.02 & 15.93 \\
GT-D20-5 & 71.0 & 182.8 & 12.41 & 170.39 & 0.07 & 0.07 & 12.48 \\
GT-D20-6 & 27.0 & 182.4 & 4.72 & 177.68 & 0.03 & 0.03 & 11.93 \\
GT-D20-7 & 31.5 & 182.4 & 5.50 & 176.90 & 0.03 & 0.03 & 10.97 \\
GT-D20-8 & 50.0 & 181.8 & 8.74 & 173.06 & 0.05 & 0.05 & 13.95 \\
GT-D20-9 & 97.0 & 183.2 & 16.95 & 166.25 & 0.10 & 0.09 & 11.16 \\
GT-D20-10 & 99.5 & 183 & 17.39 & 165.61 & 0.10 & 0.10 & 10.27 \\
Minimum & & & 3.23 & 164.60 & 0.02 & 0.02 & 10.27 \\
Maximum & & & 17.39 & 177.87 & 0.11 & 0.10 & 17.71 \\
Average & & & 9.92 & 172.53 & 0.05 & 0.06 & 13.06 \\
\hline
\end{tabular}


Table 8 Comparison between predictions and experimental results of tensile capacity

\begin{tabular}{|c|c|c|c|c|c|c|c|c|}
\hline Specimen & $\begin{array}{c}P_{n} \\
(\mathrm{kN})\end{array}$ & $\begin{array}{c}F_{b} \\
(\mathrm{kN})\end{array}$ & $\begin{array}{c}P_{u, p r e} \\
(\mathrm{kN})\end{array}$ & $\begin{array}{l}P_{u, \exp } \\
(\mathrm{kN})\end{array}$ & $R_{c}$ & $\begin{array}{c}\text { Predicted } \\
\text { Failure Mode }\end{array}$ & $\begin{array}{c}\text { Actual } \\
\text { Failure Mode }\end{array}$ & Remarks $^{\mathrm{a}}$ \\
\hline GW-D20-1 & 176.5 & 182.1 & 176.5 & 181.5 & 1.03 & Bar bond-slip & Bar fracture & $\mathrm{N}$ \\
\hline GW-D20-2 & 187.3 & 182.1 & 182.1 & 182.7 & 1.00 & Bar fracture & Bar fracture & $\mathrm{Y}$ \\
\hline GW-D20-3 & 204.9 & 182.1 & 182.1 & 182.2 & 1.00 & Bar fracture & Bar fracture & $\mathrm{Y}$ \\
\hline GW-D20-4 & 173.9 & 182.1 & 173.9 & 181.3 & 1.04 & Bar bond-slip & Bar bond-slip & $\mathrm{Y}$ \\
\hline GW-D20-5 & 166.0 & 182.1 & 166.0 & 182.0 & 1.10 & Bar bond-slip & Bar fracture & $\mathrm{N}$ \\
\hline GW-D20-6 & 174.7 & 182.1 & 174.7 & 180.8 & 1.03 & Bar bond-slip & Bar fracture & $\mathrm{N}$ \\
\hline GW-D20-7 & 178.2 & 182.1 & 178.2 & 182.7 & 1.03 & Bar bond-slip & Bar fracture & $\mathrm{N}$ \\
\hline GW-D20-8 & 185.8 & 182.1 & 182.1 & 181.6 & 1.00 & Bar fracture & Bar fracture & $\mathrm{Y}$ \\
\hline GW-D20-9 & 210.6 & 182.1 & 182.1 & 181.1 & 0.99 & Bar fracture & Bar fracture & $\mathrm{Y}$ \\
\hline GT-D20-1 & 160.5 & 182.1 & 160.5 & 181.1 & 1.13 & Bar bond-slip & Bar bond-slip & $\mathrm{Y}$ \\
\hline GT-D20-2 & 184.4 & 182.1 & 182.1 & 181.9 & 1.00 & Bar fracture & Bar fracture & $\mathrm{Y}$ \\
\hline GT-D20-3 & 202.4 & 182.1 & 182.1 & 184.8 & 1.01 & Bar fracture & Bar fracture & $\mathrm{Y}$ \\
\hline GT-D20-4 & 182.5 & 182.1 & 182.1 & 181.1 & 0.99 & Bar fracture & Bar fracture & $\mathrm{Y}$ \\
\hline GT-D20-5 & 169.7 & 182.1 & 169.7 & 182.8 & 1.08 & Bar bond-slip & Bar fracture & $\mathrm{N}$ \\
\hline GT-D20-6 & 189.0 & 182.1 & 182.1 & 182.4 & 1.00 & Bar fracture & Bar fracture & $\mathrm{Y}$ \\
\hline GT-D20-7 & 212.9 & 182.1 & 182.1 & 182.4 & 1.00 & Bar fracture & Bar fracture & Y \\
\hline GT-D20-8 & 165.6 & 182.1 & 165.6 & 181.8 & 1.10 & Bar bond-slip & Bar fracture & $\mathrm{N}$ \\
\hline GT-D20-9 & 183.6 & 182.1 & 182.1 & 183.2 & 1.01 & Bar fracture & Bar fracture & $\mathrm{Y}$ \\
\hline GT-D20-10 & 202.0 & 182.1 & 182.1 & 183.0 & 1.00 & Bar fracture & Bar fracture & $\mathrm{Y}$ \\
\hline GT-D22-11 & 217.1 & 228.4 & 217.1 & 227.3 & 1.05 & Bar bond-slip & Bar bond-slip & $\mathrm{Y}$ \\
\hline GT-D22-12 & 210.9 & 228.4 & 210.9 & 231.3 & 1.10 & Bar bond-slip & Bar fracture & $\mathrm{N}$ \\
\hline GT-D22-13 & 233.6 & 228.4 & 228.4 & 232.6 & 1.02 & Bar fracture & Bar fracture & $\mathrm{Y}$ \\
\hline
\end{tabular}

a "Y" indicates that the predicted failure modes is the same as the test, "N" indicates otherwise. 